NASA Technical Memorandum 103890

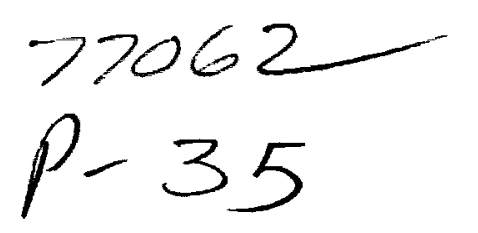

\title{
Skeletal Responses to Spaceflight
}

\section{Emily Morey-Holton and Sara B. Arnaud}

\author{
(NASA-TM-103890) SKELETAL RESPONSES TO
SPACEFLIGHT (NASA) $35 \mathrm{P}$ CSCL O6P \\ N9 2-23424 \\ Uncl as \\ $63 / 520077052$
}

December 1991

Qulck Release - This Technical Memorandum is an unedited report. It is being released in this format to quickly provide the research community with important information.

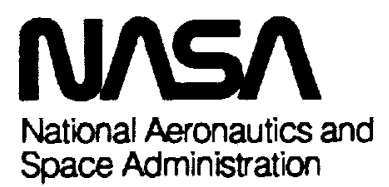



NASA Technical Memorandum 103890

\section{Skeletal Responses to Spaceflight}

Emily Morey-Holton and Sara B. Arnaud

Ames Research Center, Moffett Field, California

December 1991

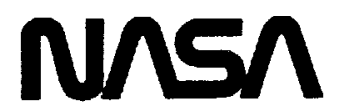

National Aeronautics and

Space Administration

Ames Research Center

Moffett Field, California 94035-1000 

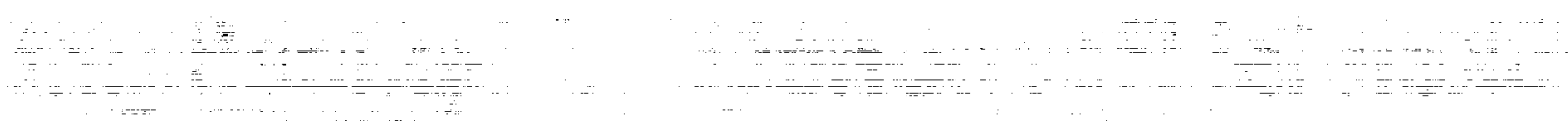


\section{CONTENTS}

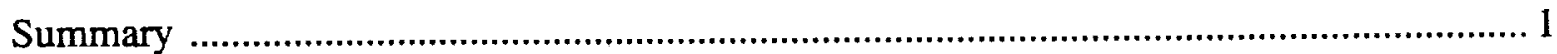

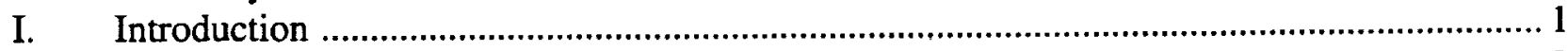

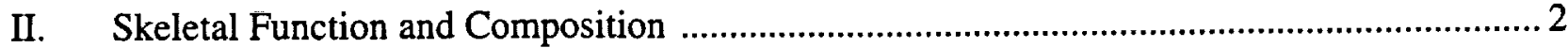

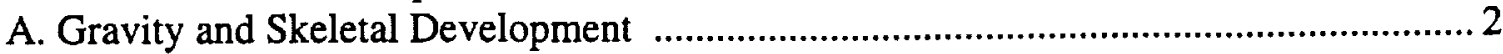

B. Skeletal Composition and Function ……………………........................................... 2

C. The Biomineralization Process ………………………….............................................. 3

III. Skeletal Changes in Humans During Spaceflight and Bedrest ............................................. 4

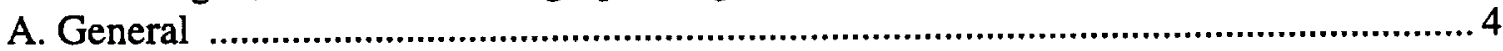

B. Results from Spaceflights ......................................................................................

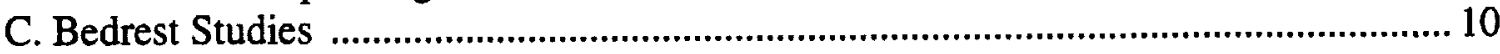

IV. Space-Induced Skeletal Changes in Growing Rats ......................................................... 10

A. General ............................................................................................................. 10

B. Serum Parameters ................................................................................................ 11

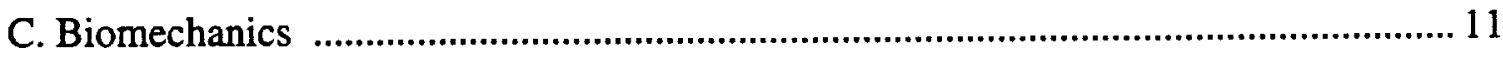

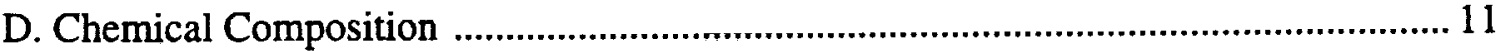

E. Maturation and Growth ............................................................................................ 13

F. Cancellous Bone and Cell Populations ..................................................................... 15

G. Non-weightbearing Bones .......................................................................................... 16

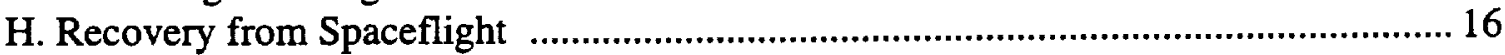

I. Interpretation ...................................................................................................... 15

V. Ground-Based Unloading-Induced Skeletal Changes in Growing Rats ................................ 18

A. General ................................................................................................................ 18

B. Serum Parameters ................................................................................................ 19

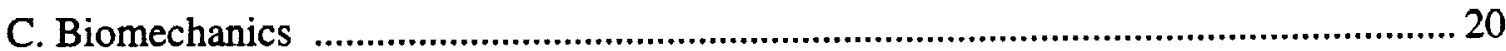

D. Chemical Composition ............................................................................................... 20

E. Metabolism, Maturation, and Growth ........................................................................ 20

F. Cancellous Bone and Cell Populations ……………………....................................... 21

G. Bone Mass Redistribution ...................................................................................... 21

H. Recovery from Suspension ....................................................................................... 21

I. Compariston with Flight Data .................................................................................... 21

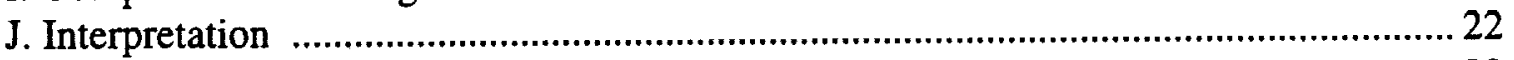

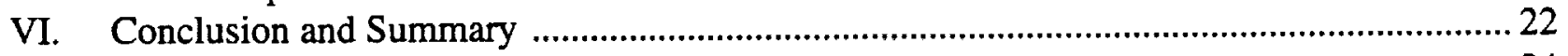

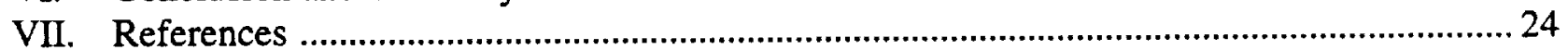




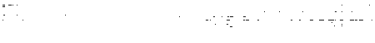

$-$

(n) 


\section{SUMMARY}

The role of gravity in the determination of bone structure has been elucidated by observations in adult humans and juvenile animals during and after spaceflight. The response of the skeleton to a new environment that imposes different biomechanical stresses is complicated by the skeleton's dual function as a support structure and as a mineral reservoir. The transport of minerals is regulated and influenced by organ systems (i.e., cardiovascular, muscular, renal, gastrointestinal) whose anatomy and metabolism are also affected by microgravity. This review deals almost exclusively with the observed and potential effects of spaceflight on bone, but some findings from other body systems are also cited. The primary response of bone tissue to microgravity is at the interface of mineral and matrix, in the process of biomineralization. This response is manifested by demineralization or retarded growth in some regions of the skeleton, and hypermineralization in others. The most pronounced effects are seen in the heel bone and the skull, the most distally located bones relative to the heart. Whereas quantitative losses of mineral from the whole skeleton are relatively small, regional or localized areas of change during spaceflight could seriously impair the support function of the skeleton on return to Earth. Ground-based flight simulation models (head-down bed rest (human) and the rat tail-traction system) that focus on changes in bone structure at the molecular, organ, and whole-body levels are described and compared to flight results. On Earth, the morphologic and compositional changes in the unloaded bones are very similar to changes during flight; however, the ground-based changes appear to be more transient. In addition, a redistribution of bone mineral in gravity-dependent bones occurs both in space and during head-down positioning on Earth. Longitudinal data have provided considerable information on the influence of endocrine and muscular changes on bone structure after unloading.

\section{INTRODUCTION}

The skeletal system of vertebrate animals, including man, has been evolving for millions of years under the constant influence of gravity. Gravitational loading and function have determined the shape, size, composition, and strength of bones. If gravitational force is decreased, then changes in the skeleton will occur, but the extent and duration of these changes is not known. Data from spaceflights suggest that the changes in bone and calcium metabolism begin early in flight and continue for at least three months. Major concerns for long duration spaceflight include: 1) decreased skeletal strength which might complicate return to earth as well as human exploration of planets, and 2) deficits in the skeletal mineral pool, particularly calcium and phosphorus, which plays a critical role in maintaining the function of most cell and organ systems.

This chapter will briefly review gravity and skeletal development, bone composition, and bone regulation, and focus on spaceflight data and ground studies in both man and growing rats. The hypothesis that has been formulated states that skeletal adaptation to weightlessness primarily alters the biomineralization process. The consequence of this alteration is a decrease in mass and strength of the weight-bearing bones. Primarily from ground-based studies, we have become aware of the gravity-induced relocation of bone mineral from one area of the skeleton to another. The response of the skeletal system to spaceflight is highly complex with losses and redistribution of bone mineral operating simultaneously to adapt bone architecture and composition to a new environment. 


\section{SKELETAL FUNCTION AND COMPOSITION}

\section{A. Gravity and Skeletal Development}

Earth's gravitational force has been the most constant environmental factor throughout the course of evolution of species. Gravity is a primary driver in determining the type and amount of support necessary for skeletal structures. Gravity influences not only the size, shape, and strength of bone but also the vascular supply and fluid flow to the skeletal system. The importance of gravity on skeletal mass has been studied by many investigators over many years. In the 17 th century, Galileo examined bones of animals of increasing size and noted changes in bone size and shape similar to those incorporated by architects into load-bearing elements of structures of increasing size and wrote about this observation in his Principle of Similitude. In the late 19th century, Wolff studied bone form and function and contributed what is now called Wolff's law: changes in function or loading cause changes in bone structure in accordance with mathematical laws. His law predicts mechanical effects on bone architecture but does not define the mathematics or the cause of such change. D'Arcy Thompson (1917) noted that to build a house or to construct an animal beyond a certain size on Earth required altering the design or materials and showed that the shapes of organs of various plants and animals can be accurately described using geometric figures defined by simple equations. Frost (1990) reviewed the bone biomechanics literature, redefined Wolff's Law, and provided testable theories for mechanical influence on bone modeling, bone remodeling, hyaline cartilage modeling, and intact fibrous tissue. Gravitational loading provides the mechanical stimulus necessary for bone growth, development, and maintenance. However, adequate diet, endocrine milieu, growth factors, renal and gut function, blood flow, and blood pressure are necessary for proper translation of the stimulus into an appropriate bone structure.

During growth, the force imposed by gravity causes bone to increase simultaneously in mass and strength; as a result, larger animals have larger and stronger bones. Gravitational loading may play a role in fusing some of the 350 bones of neonates so that the total number of individual bones in the adult human skeleton is reduced to about 200 . The influence of gravity is also obvious in the skeletal differences in species from marine vertebrates to large land mammals. In fact, the larger the land animal, the greater the fraction of the body represented by skeletal mass. For example, a mouse with a body mass of about $20 \mathrm{~g}$ has a skeleton which is about $5 \%$ of its body mass, a $5 \mathrm{~kg}$ dog's skeleton is about $13 \%$, a $75 \mathrm{~kg}$ man's is about $17 \%$, and a $7000 \mathrm{~kg}$ elephant's is about $27 \%$ (Smith, 1975). Marine mammals, on the other hand, do not appear to scale with body mass, but show constant skeletal proportions (about 15\% of body mass) regardless of size. These mammals spend a significant portion, if not all, of their lives neutrally buoyant. A whale washed ashore will suffocate within minutes because its ribs are not designed to resist the force of gravity.

With the advent of long duration spaceflight, function and loading of the skeletal system will change and these changes will reshape the type and amount of skeletal tissue. How dramatic these changes will be over several generations is not known.

\section{B. Skeletal Composition and Function}

Bone is a living, dynamic tissue characterized physically by hardness and rigidity and histologically by a sparse cell population relative to extracellular substance. Bone is the strongest 
biological material on earth on a weight basis. It is composed of an organic matrix or osteoid which conveys strength and stability and the inorganic mineral hydroxyapatite which contributes stiffness. Bone-forming cells, osteoblasts, synthesize and secrete the organic component (primarily collagen, other proteins, and polysaccharides) which goes through an incompletely defined maturation process prior to mineralization with hydroxyapatite crystals. The activity of osteoblasts appears to be both systemically and self regulated. Factors such as transforming growth factor, insulin-like growth factors, prostaglandins, interleukins and interferon are involved in local regulation; systemic regulation is through hormones including parathyroid hormone, growth hormone, glucocorticoids, thyroid hormones, insulin, estrogen, and possibly the vitamin D hormone (Raisz, 1988). The osteoblast, in addition to producing osteoid, may also be responsible for orienting collagen during secretion to appropriately align the molecule for cross-linking events. Ultimately, it is responsible for biomineralization. Bone-resorbing cells, osteoclasts, secrete enzymes and provide an acidic environment necessary for dissolving bone mineral and allowing access to bone matrix for degradation (Baron, 1990). The numbers and activities of these two cell types ultimately determine bone structure.

The skeleton has two major functions. In addition to providing support for the body and protection for the internal organs and bone marrow, the skeleton is a very important mineral reservoir that works in concert with the kidneys and intestine to maintain the calcium (Ca) levels in extracellular fluids within a narrow range. All three target organs, regulated by systemic calciotropic hormones, control $\mathrm{Ca}$ metabolism. This rigid control of $\mathrm{Ca}$ is essential for normal functioning of many processes including muscle contraction, cardiac rhythmicity, blood clotting, nerve function, and hormone secretion. Bone contributes to the calcium pool with both a readily exchangeable calcium reservoir which is in equilibrium with plasma calcium and a much larger stable pool of calcium that is slowly exchangeable. During skeletal unloading, alterations in bone calcium fluxes may initiate, rather than reflect, changes in calciotropic hormones. However, the interaction of metabolic processess with gravitational loading is poorly understood.

\section{The Biomineralization Process}

The primary site of the bone response to unloading appears to be in the mineralization of matrix. Biologically controlled mineralization is a very complex process (Eanes, 1989; Lowenstam and Weiner, 1989; Puzas, 1990; Termine, 1990). The process in bone begins with one or more undefined stimuli. Fluid flow (Reich et al., 1990) and cell deformation induced by cyclic, mechanical tension (Binderman et al., 1984; Hasegawa et al., 1985; Buckley et al., 1988) or pressure (Ozawa et al., 1990; Klein-Nulend et al., 1987) are reported to be important mediators of the process. Fluid flow under hydrostatic pressure would be forced through bone interstices; the fluid movement may deform cells and displace and separate positive counterions from fixed negative charges located in the bone matrix, thus producing an electrical potential gradient in the direction of fluid flow (Gross and Williams, 1982; Binderman et al., 1984; Pollack et al., 1984; Erickson, 1976). The stimulus or stimuli may necessitate differentiation of bone progenitor cells into osteoblasts (Roberts and Morey, 1985 ) or may directly stimulate these cells to elaborate proteins and polypeptides including collagen and non-collagenous proteins, enzymes associated with mineralization, and various local growth factors. The organic matrix is secreted from the cell via a cytoskeletal network and organized extracellulary where mineralization will occur. Proteoglycan granules which periodically associate with the cross-banding of collagen fibrils in the matrix may be necessary for normal mineralization 
(Nagomi and Ochira, 1988). The cells form tight junctions or vesicles which act as a barrier to trap ions and create a saturated solution; calcified cartilage and woven bone have been shown to mineralize using matrix vesicles, whereas lamellar bone may mineralize directly onto a localized surface. Both processes are thought to involve an anionic non-collagenous protein which binds $\mathrm{Ca}$, has an active surface conformation closely matched structurally and complemented electrically to the contiguous surface of the overlying crystal nucleus, and is securely anchored to the surface of the collagen fiber. Crystal growth is initiated, controlled, and terminated by unknown mechanisms thought to involve the osteoblast. Crystals are aligned with their crystallographic $c$-axes parallel to the fiber axis as long as ion binding is sufficiently strong to keep the growing crystals from detaching from the collagen surface and rotating into other orientations. The sequence of these cellular events is being defined in mineralizing bone cell cultures (Gerstenfeld et al., 1988; Aronow et al., 1990; Owen et al., 1990). The mineralization process is regulated by local factors and systemic hormones (Canalis, 1990). Spaceflight and skeletal unloading on Earth appear to interfere with this process and, hence, cause changes in bone structure. The site(s) and extent of the mineralization defect in both growing animals and crew members on space missions are unknown.

\section{SKELETAL CHANGES IN HUMANS DURING SPACEFLIGHT AND BEDREST}

\section{A. General}

Loss of skeletal mass is a major medical concern for long duration spaceflight (Nicogossian et al., 1989). This concern arose primarily from the elegant biomedical studies conducted aboard the Skylab missions in 1973. These data showed that urinary calcium increased early and continued throughout spaceflight (Whedon et al., 1977), that fecal calcium excretion increased almost linearly after approximately one month in space (Rambaut and Johnston, 1979), that detectable mineral loss in the heel bone occurred in some crew members as early as 59 days of flight (Vogel et al., 1977), and that the lost bone mineral was not replaced five years following flight (Tilton et al., 1980).

Review of the Skylab data combined with information from recent studies provide new insights into the potential changes in the skeleton during long term spaceflights. In addition, 1 to 13 week studies in growing male rats indicate that bone strength may be more severely affected than bone mineral (Spengler et al., 1983; Patterson-Buckendahi et al., 1987; Shaw et al., 1988; and Vailas et al., 1990) and that skeletal changes may be regional (LeBlanc et al., 1985; Arnaud and MoreyHolton, 1989). Other studies indicate that 1) changes in bone and calcium metabolism begin very early in flight (Morey-Holton et al., 1988), 2) the amount of skeletal change is dependent upon the rate of modeling or remodeling of the system and the loading history of the bone (Dalen and Jacobson, 1974), 3) a redistribution as well as a loss of mineral within the skeletal system may occur (Arnaud and Morey-Holton, 1989, LeBlanc et al., 1987; Roer and Dillaman, 1990), and 4) the skeletal changes and adaptive responses to the unique environment of space may vary greatly between individuals. These findings, to which can be added a body of knowledge documenting depressed formation and loss of bone in space, are leading to the awareness that these phenomena are only part of a complex physiologic and biomechanical adaptation of the skeleton during weightlessness. 


\section{B. Results from Spaceflights}

\section{General}

The most elegant human biomedical flights were those of the Skylab series in 1973. The Skylab satellite was deployed and then visited by three groups of three astronauts; the first group remained for 28 days, the second for 59 days, and the last for 84 days. Samples were collected preflight, inflight, and postflight. Of the over 100 experiments and observations conducted during the three missions, 16 obtained physiological data and three of the 16 studies investigated bone loss, mineral balance, and hormone status (Johnston and Dietlein, 1977). Metabolic balance techniques were used for analyzing changes in whole body calcium, phosphorus, and nitrogen (Whedon, 1979). This technique required 24-hour urine and fecal collections as well as dietary regulation. Dietary intake was controlled within the constraints of flight packaging, food types allowed, and personal preferences of the crews. Supplemental mineral tablets were prescribed as needed. Dietary regulation began 21 to 31 days before flight (depending on the length of the mission) and continued for 17 or 18 days postflight. During flight, 24-hour urines were collected, and $120 \mathrm{ml}$ aliquots were frozen for analysis. Entire stool samples were dried during flight. Serum samples were taken at different intervals during the missions and returned to Earth for analysis (Leach and Rambaut, 1977).

An interval of more than 10 years separates the comprehensive work from the Skylab missions from the only other American flight experiment on calcium metabolism carried out on the 8-day Spacelab mission (Morey-Holton et al., 1988). Blood samples were collected from four astronauts for the measurement of calciotropic hormones. A few of the Soviet reports on aspects of bone and calcium metabolism are noteworthy. There is documentation of the density of the os calcis after 56.5 months in space (Stupakov et al., 1984), an observation of the response of two cosmonauts to an oral calcium load after 5 months in space (Grigoriev et al., 1982), and a histologic analysis of some of the bones of three cosmonauts who perished after a month in space (Prokhonchikov et al., 1984).

Samples and measurements taken during a spaceflight are extremely difficult to realize due to mission constraints. The paucity of inflight data creates critical gaps in our knowledge of potential factors that might be involved in the response of calcium metabolism to spaceflight, for example acid-base balance, kidney and intestinal function, fluid flow and pressures, etc.

\section{Calcium metabolism}

Modest increases in serum calcium and phosphorus occurred in the nine astronauts during the Skylab missions (Leach and Rambaut, 1977). Concurrent measurements of immunoreactive parathyroid hormone, a major regulator of circulating calcium, showed no changes in this parameter. Indications that the normal negative feedback relationship between serum calcium and parathyroid hormone is undisturbed during the first week in space were obtained during the SL-2 mission (Morey-Holton et al., 1988). Biologically active parathyroid hormone and a profile of derivatives of vitamin $\mathrm{D}$ were assayed. The absolute values of serum minerals and hormones were within the normal range, except for the first day value for serum 1,25-dihydroxyvitamin D which was increased transiently to $57 \%$ of preflight values. Whether the vitamin D hormone is involved in the egress of calcium from the skeleton during the first 24 hours of flight is entirely speculative, but its wellknown actions in facilitating calcium transport out of cells and in enhancing bone resorption are consistent with this possibility. 
The more generally accepted concepts of the regulation of calcium homeostasis in the long term situation of disuse osteoporosis, the clinical model for spaceflight, are illustrated in Figure 1, which is based on observations during four months of paralysis (Stewart et al., 1982). It suggests that the initial response to spaceflight is altered bone calcium fluxes during which bone resorption exceeds bone formation. The increase in serum calcium created by this change causes suppression of parathyroid hormone. The renal synthesis of the active derivative of vitamin $\mathrm{D}$ is regulated by parathyroid hormone, and in turn, is reduced. Depression of the 1,25-dihydroxyvitamin D/parathyroid hormone axis maintains calcium homeostasis by actions on the kidney (reduction of the renal tubular reabsorption of calcium) and intestine (reduction of the intestinal absorption of calcium). These responses to inactivity could be the source of the calciuria and negative calcium balance that were observed in Skylab.

The responsivity of the calcium endocrine system following 140 days in space was evaluated by an oral calcium challenge given to two cosmonauts a few days after landing (Grigoriev et al., 1982). Serum ionized calcium and urinary calcium excretion were higher postflight than preflight after the same calcium dose. Levels of parathyroid hormone were appropriately lower in response to the test dose of calcium postflight than preflight. This study suggests a normal response of parathyroid hormone postflight, but an alteration in calcium metabolism, at the level of kidney, intestine, or bone, that is difficult to identify.

In spite of diets comprised of recommended allowances (Harper, 1980), the Skylab astronauts still exhibited some degree of negative calcium balance. An excellent critique (Parfitt, 1981) of the fecal and urinary data from Skylab suggested that renal calcium losses accounted for most of the mineral loss. There is, however, enormous individual variation in the calcium balance results. Other endocrine problems in spaceflight such as hypercortisolism, a recognized cause of malabsorption of dietary calcium, need to be considered. In-flight measurements of serum cortisol during Skylab showed occasional increases while urinary 17 -ketosteroids appeared to increase more consistently throughout the flight (Leach and Rambaut, 1977).

\section{Bone changes}

Photon absorptiometry was used to study the density of the left calcaneus (heel bone) and radiusulna complex (wrist) during the Skylab experiment (Vogel et al., 1977; Table 1). Bone losses from the calcaneus ranging from 4 to $7 \%$ were reported in three out of six astronauts who were in Skylab for more than one month. Decreases in bone mineral ranging from 3 to $10 \%$ were found in five out of six cosmonauts who were in space from 75 to 184 days (Stupakov et al., 1984). The severity of loss appears to increase with the increase in mission duration. However, no change was found in bone density in the arm of any crewmember of Skylab suggesting that bone loss was limited to the weight-bearing bones (Vogel et al., 1977).

Similar measurements of the os calcis taken five years after Skylab were published by Tilton et al. (1980). They compared their data with the Skylab preflight baseline value and suggested that the data were superficially consistent with a statistically significant long-term loss of bone mineral following spaceflight, but urged caution in interpretation of the differences. When the Skylab os calcis density data immediately postflight are compared with the Tilton measurements, it is seen that the two crewmembers who lost more than $7 \%$ bone mass during the flight gained bone mass during the recovery years (Table 1 bold print). 


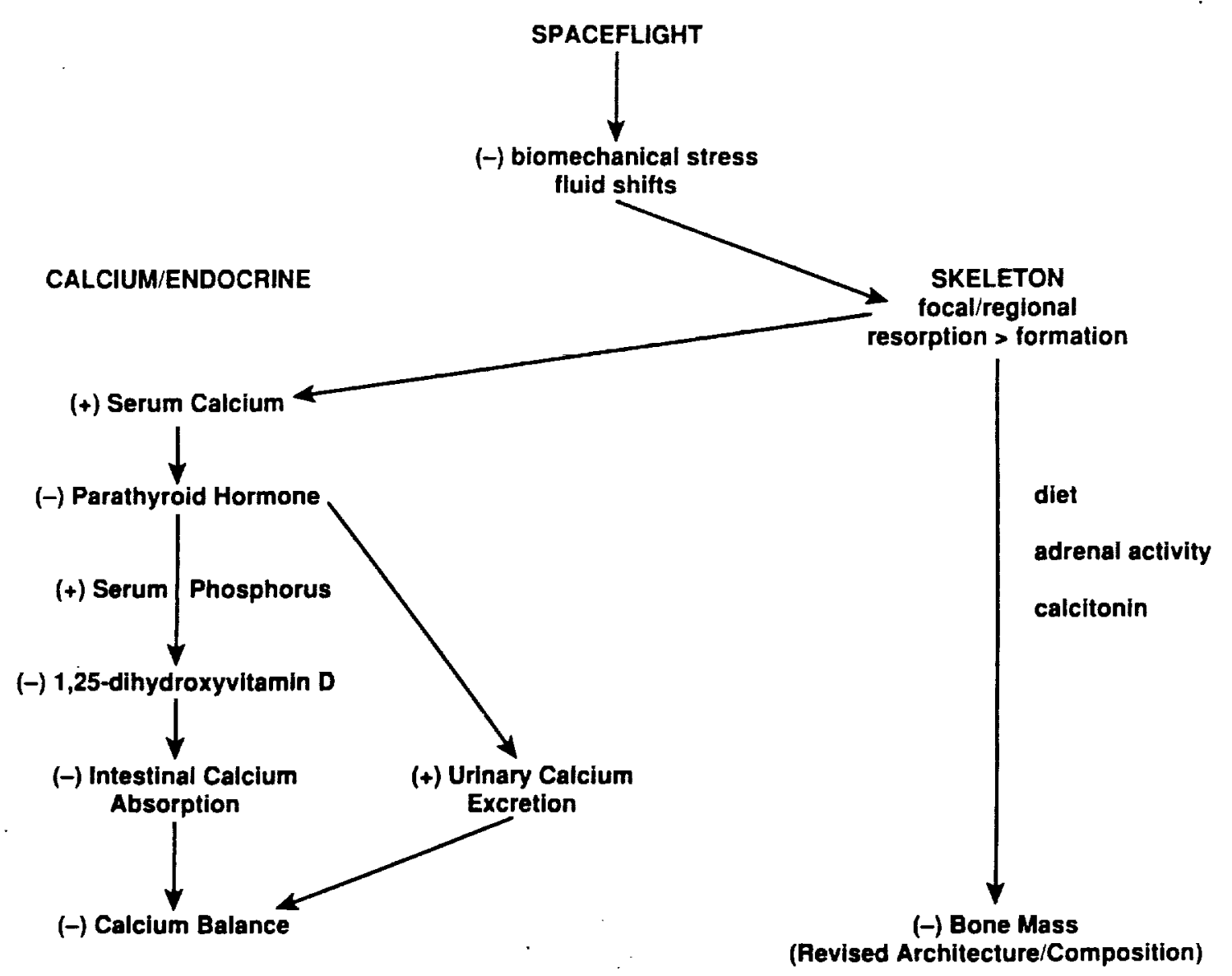

Figure 1. Hypothetical scheme of the effects of space flight on calcium metabolism and bone mass. The two principal stimuli to the skeleton as a unit are reduced biomechanical stress and cephalad fluid shifts. The rate of resorption of bone which exceeds that of formation is believed to be the overall skeletal response. Bone mineral apposition is reduced more in the lower weight bearing regions than in the upper skeleton. During spaceflight the biomechanical forces on a single bone may be altered to inhibit or stimulate formation in adjacent areas or different regions determined by bone function and the cardiovascular system. Changes in bone cell activity and the demand for calcium are reflected by a modest increase in circulating calcium, usually within the normal range, but sufficient to depress the serum parathyroid hormone level. This hormone changes renal tubular reabsorption of calcium and thus its urinary excretion, as well as the renal synthesis of the vitamin $\mathrm{D}$ hormone, in the directions indicated. These changes drive the calcium balance to a negative value. The role of diet, adrenal activity, and calcitonin are listed as variables that may have a large influence on generalized skeletal mass at an individual level. These factors may account for much of the individual variation in bone changes in crews of spaceflights and subjects in ground-based studies. Caloric restriction, calciuric elements in the diet, an hyperactive adrenal, and reduced levels of calcitonin tend to promote generalized bone loss. Not illustrated is the interaction between the hormones of the calcium endocrine system and bone cells, whose activities are the ultimate determinants of bone microstructure. 


\section{TABLE 1. SKYLAB LEFT OS CALCIS MINERAL $\left(\mathrm{mg} / \mathrm{cm}^{2}\right)$}

\begin{tabular}{|c|c|c|c|c|c|c|}
\hline & $\operatorname{Pre}^{1}$ & Post $^{2}$ & $\begin{array}{l}\% \text { Change } \\
\text { (Post vs Pre) }\end{array}$ & $5 \mathrm{yr}^{1}$ & $\begin{array}{l}\% \text { Change } \\
\text { (5yr vs Pre) }\end{array}$ & $\begin{array}{l}\% \text { Change } \\
\text { (5yr vs Post) }\end{array}$ \\
\hline \multicolumn{7}{|l|}{ SKYLAB 2} \\
\hline Commander & 390 & 392 & +0.5 & 352 & -9.9 & -10.3 \\
\hline Science Pilot & 631 & 626 & -0.9 & 612 & -3.0 & -2.1 \\
\hline Pilot & 652 & 669 & +2.7 & 594 & -8.9 & -11.3 \\
\hline CR & 455 & 466 & +2.4 & 454 & -0.2 & -2.5 \\
\hline CA & 519 & 525 & +1.2 & 542 & +4.4 & +3.2 \\
\hline JV & 617 & 606 & -1.7 & 621 & +0.7 & +2.5 \\
\hline \multicolumn{7}{|l|}{ SKYLAB 3} \\
\hline Commander & 473 & 484 & +2.3 & 456 & -3.4 & -5.6 \\
\hline Science Pilot & 527 & 488 & -7.4 & 491 & -6.8 & +6.8 \\
\hline Pilot & 637 & 646 & +1.4 & 654 & +2.6 & +6.8 \\
\hline $\mathrm{CA}$ & 519 & 530 & +2.1 & 542 & +4.4 & +2.3 \\
\hline JV & 617 & 616 & -0.2 & 621 & +0.7 & +0.9 \\
\hline \multicolumn{7}{|l|}{ SKYLAB 4} \\
\hline Commander & 518 & 522 & +0.7 & 510 & -1.6 & -2.3 \\
\hline Science Pilot & 708 & 676 & -4.5 & 653 & -7.7 & -3.4 \\
\hline Pilot & 556 & 522 & -7.9 & 526 & -7.1 & +8.2 \\
\hline $\mathrm{CA}$ & 519 & 527 & +1.5 & 542 & +4.4 & +2.9 \\
\hline JV & 617 & 622 & +0.9 & 621 & +0.7 & -0.2 \\
\hline
\end{tabular}

1Data from Tilton et al, 1980

$\mathbf{2}_{\text {data calculated using preflight baseline and } \% \text { change (post vs pre) }}$

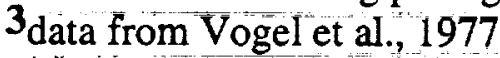

$\mathrm{CR}, \mathrm{CA}$, and $\mathrm{JV}=$ controls

Pre $=$ preflight baseline, Post $=$ postflight, bold type $=$ greater than $7 \%$ loss during flight

Another interesting observation is found in the report of Thornton and Ord (1977). These investigators showed that low caloric intakes during flight could partly explain the loss of weight that occurs during spaceflight (Figure 2). Data points from six of the nine_crewmembers defined a relationship between weight loss and caloric intake. The other three astonauts exhibited greater weight loss than might be predicted from caloric intake. According to Thornton and Ord, these "were also the three crewmen with the smallest amount of body fat--all three well under 10 percent." Since low body fat is indicative of intensive exercise and the heel bone mass is dependent on exercise (Dalen and Jacobson, 1974), the loss of bone mass in these crewmembers may have been due to the change in exercise status or diet during spaceflight.

One factor associated with individual variation in demineralization of the os calcis is the relative amounts of exercise before and during the flight. Exercise countermeasures are now firmly established, and are routinely performed by astronauts and cosmonauts. The failure of these 


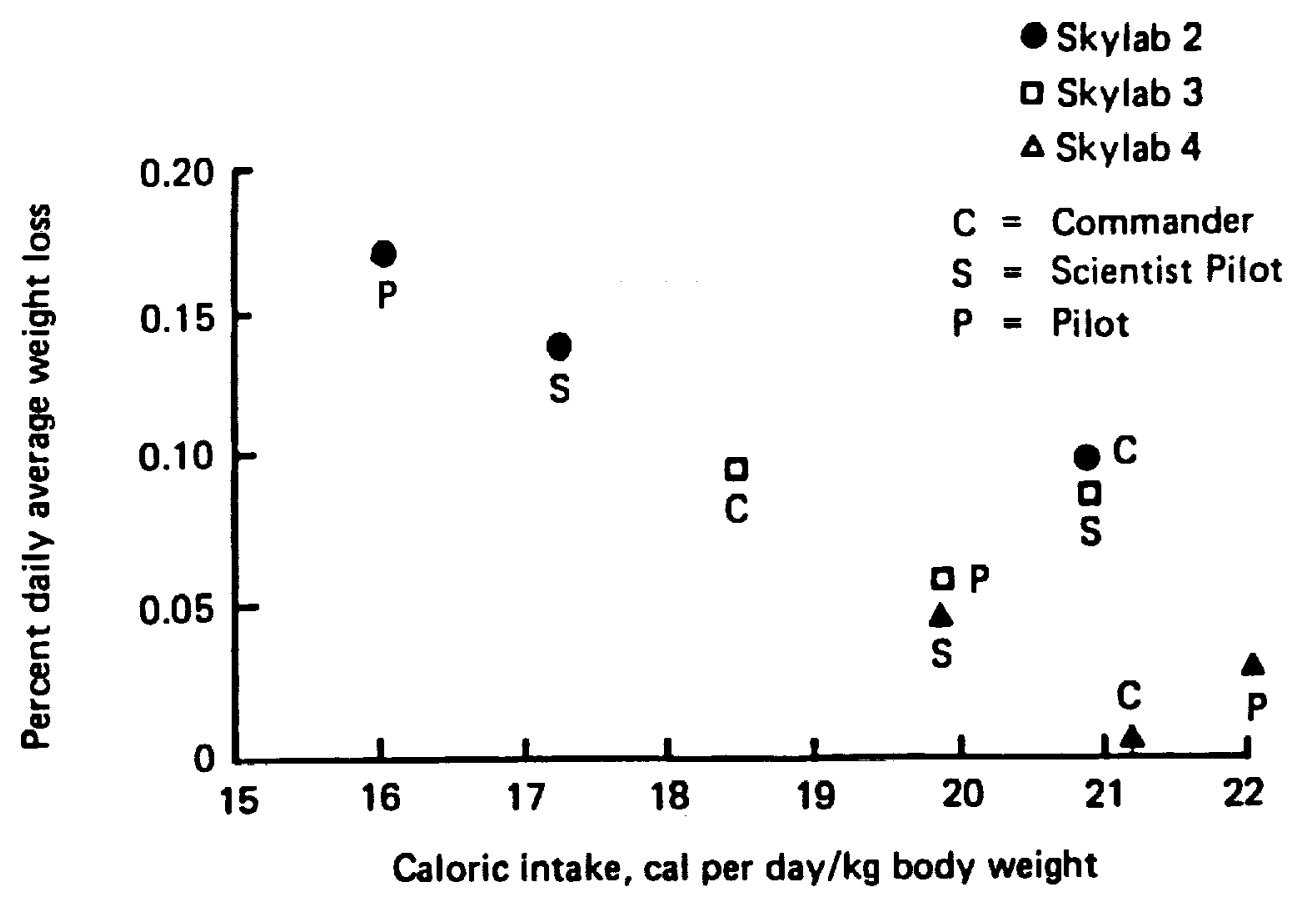

Figure 2. Weight loss vs caloric intake for the nine Skylab astronauts inflight. Weight loss, expressed as a daily average percent, is plotted against caloric intake. An intake of less than 20 cal per day per kilogram body weight is associated with more than .05 percent daily weight loss. The SL3 scientist pilot and SL4 pilot who lost more weight than might be predicted from the caloric intake were also the two astronauts who lost the most bone (Table 1). Reproduced with permission from Thornton and Ord, 1977.

exercises to prevent demineralization of at least the os calcis suggests that we do not sufficiently understand the forces to be applied and the exercises needed to maintain the mineral content and strength of the bone.

Examination of the lumbar spine of four cosmonauts by quantitative computerized tomography has shown little change after 6 months in space (Oganov et al., 1990). Even in the comprehensive analysis of the bones of three cosmonauts who after one month in space died by an accident during descent, morphologic changes were only found in the weightbearing lower extremities. There were fewer vascular channels and the femur showed some increase in the porosity of the epiphysis and diaphysis (Prokhonchikov et al., 1984). Since the differences between control and cosmonaut samples were highly variable, it is difficult to attribute the changes to the effect of microgravity.

Increased bone resorption during flight would be expected to increase the urinary excretion of organic matrix derivatives as well as that of calcium and phosphorus. Urinary hydroxyproline (Rambaut and Johnston, 1979) and total hydroxylysine (Leach and Rambaut, 1977) excretion have been reported to increase during the Skylab missions, but urinary excretion of total and peptide bound hydroxyproline and hydroxylysine glycosides has also been reported as unchanged in the three crew members of Skylab 4 (Claus-Walker et al., 1977). 
Significant changes in bone are undoubtedly occurring during spaceflight even though whole body loss of bone mass may be minimal. In fact, the changes occurring in the skeletal tissue during spaceflight are probably very complex and may affect bone structure more than bone mass (Arnaud and Morey-Holton, 1990).

\section{Bedrest Studies}

The results of bedrest studies of calcium metabolism and bone changes in humans have recently been reviewed (Arnaud et al., 1986). They show that the calcium endocrine system and bone respond promptly (within days) to changes in body position.

Negative calcium balance and demineralization of the os calcis similar to that found in astronauts have been reported after 5 and 17 weeks of bedrest (LeBlanc et al., 1987; LeBlanc et al., 1990). Recent studies utilized the new dual photon absorptiometry technique to assess both bone density and calcium balance by determining whole body calcium. Quantitative estimates of whole body calcium loss by densitometry were $1.4 \%$ after 17 weeks of horizontal bed rest, in fair agreement with balance data showing an average mineral loss of $1.7 \%$ in the same subjects (LeBlanc et al., 1990). These studies also demonstrated a redistribution of bone mass (with the largest loss in the os calcis, slight losses in lumbar spine, pelvis, tibia, and femur, no change in the thoracic spine, arms, ribs, or Ward's triangle, and a gain in bone mineral in the skull) rather than a generalized demineralization of the skeleton (LeBlanc et al., 1990; Arnaud et al., 1989).

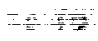

The redistribution of bone mineral combined with histologic studies of bone biopsies of the iliac crest after 120 days of bed rest emphasize the adaptive process that the skeleton as a whole undergoes to meet new functional demands. Increases in resorption surfaces and depressed rate of mineralization without change in bone volume was reported in three healthy volunteers after 4 months of bed rest (Vico et al., 1987b). This morphology contrasts with similar surface activities associated with reductions in tissue volume observed in paraplegics. Morphologic measurements on a two-dimensional level may not be adequate to demonstrate what may be three-dimensional changes in microarchitecture in the adaptation to altered loading of bone in bed rest.

\section{SPACE-INDUCED SKELETAL CHANGES IN GROWING RATS.}

\section{A. General

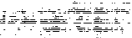

Indications of acute changes in bone structure in young, growing, male rats flown on multiple Soviet Cosmos flights and one Space Shuttle mission have been reported. In the reports cited in this section, the bones analyzed are specified since the effects of flight are not consistent from bone to bone and even from site to site within the same bone. Existing data are from male rats either 8-9 or $12 \mathrm{wk}$ of age in space for 7 to 19 days. The Soviets also flew pregnant rats for $5 \mathrm{~d}$ on Cosmos 1514 . The primary affect of spaceflight on bone appears to be delayed bone maturation specifically a defect in mineralization of matrix. The extent of the defect appears related to the growth rate of the rat and the duration of the flight. 


\section{B. Serum Parameters}

The only opportunity to obtain blood samples for analysis of hormones and markers of bone metabolism from rats has been immediately postflight. While the short half-lives of these compounds usually preclude inferences about their status in-flight, some useful information has been obtained from measurements of osteocalcin and alkaline phosphatase, products of the osteoblast cell, in postflight serum samples. Serum osteocalcin was markedly depressed after spaceflight. This may have been due to the reduced number of osteoblasts in bone, to excess glucocorticosteroids, or to both (Patterson-Buckendahl et al., 1985). The vitamin D hormone was not changed (PattersonBuckendahl et al., 1985) and serum alkaline phosphatase usually was unchanged, while corticosterone levels were not different (Spacelab 3) or increased (most Cosmos flights) compared to control levels.

\section{Biomechanics}

During spaceflight in growing rats, biomechanical parameters do not increase proportional to the increase in mass in the femur (Spengler et al., 1983), tibia (Shaw et al., 1988) and humerus (PattersonBuckendahl et al., 1985; Shaw et al., 1988). The details are shown in Figure 3. Defects in strength are corrected by inflight centrifugation at IG (Spengler et al., 1983). The deficit in mechanical strength could be due to multiple factors including material properties and cross-sectional geometry. A density decrease was noted in the tibia (Shaw et al., 1988), but not the humerus (Shaw et al., 1988) or femur (Spengler et al., 1983). Changes in cross-sectional geometry were not implicated in the 7d SL3 flight or the longer duration Cosmos missions. In fact, the modulus of elasticity in the humerus was as severly affected as stiffness (Shaw et al., 1988). However, the humeri of rats on Cosmos 1887 (12.5d flight) showed changes in flexural rigidity but not elastic moduli indicating changes in geometry rather than material properties of cortical bone (Vailas et al., 1990a). This flight landed off course, requiring 30 hours to transport the rats to the field laboratory and another 18 to 26 hours to complete the experiment; some recovery from spaceflight effects could have occurred. Vertebrae from rats on the same flight showed decreased strength and stiffness coupled with a smaller proportion of mature hydroxypyridinoline cross-links suggesting a delayed maturation (Zernicke et al., 1990). To understand the changes in bone biomechanics, it is important to review available data on other skeletal effects of spaceflight.

\section{Chemical Composition}

In general, the relative concentrations of mineral and matrix determined by analsyis of whole bone powder were unchanged, but localized regions of long bones showed deficits in mineral and changes in the composition of the matrix. The lack of dramatic changes in whole bone powder was not surprising since the majority of bone mass was formed prior to flight. The amount of bone in cross-section can be used to approximate the percentage of bone accumulated during flight (Table 2). Flight rats add 3 to $12 \%$ of total bone mass while controls add between 5 and $20 \%$ depending on rat age, flight duration, and sampling site. The control groups were killed 2-7 days after the flight group rather than on the same day allowing additional accumulation of bone; thus, the control area, if anything, was smaller than suggested by the data. The difference in accumulated mass between flight and controls during the flight period ranged from $<1 \%$ to about $7 \%$ which is within the range of 

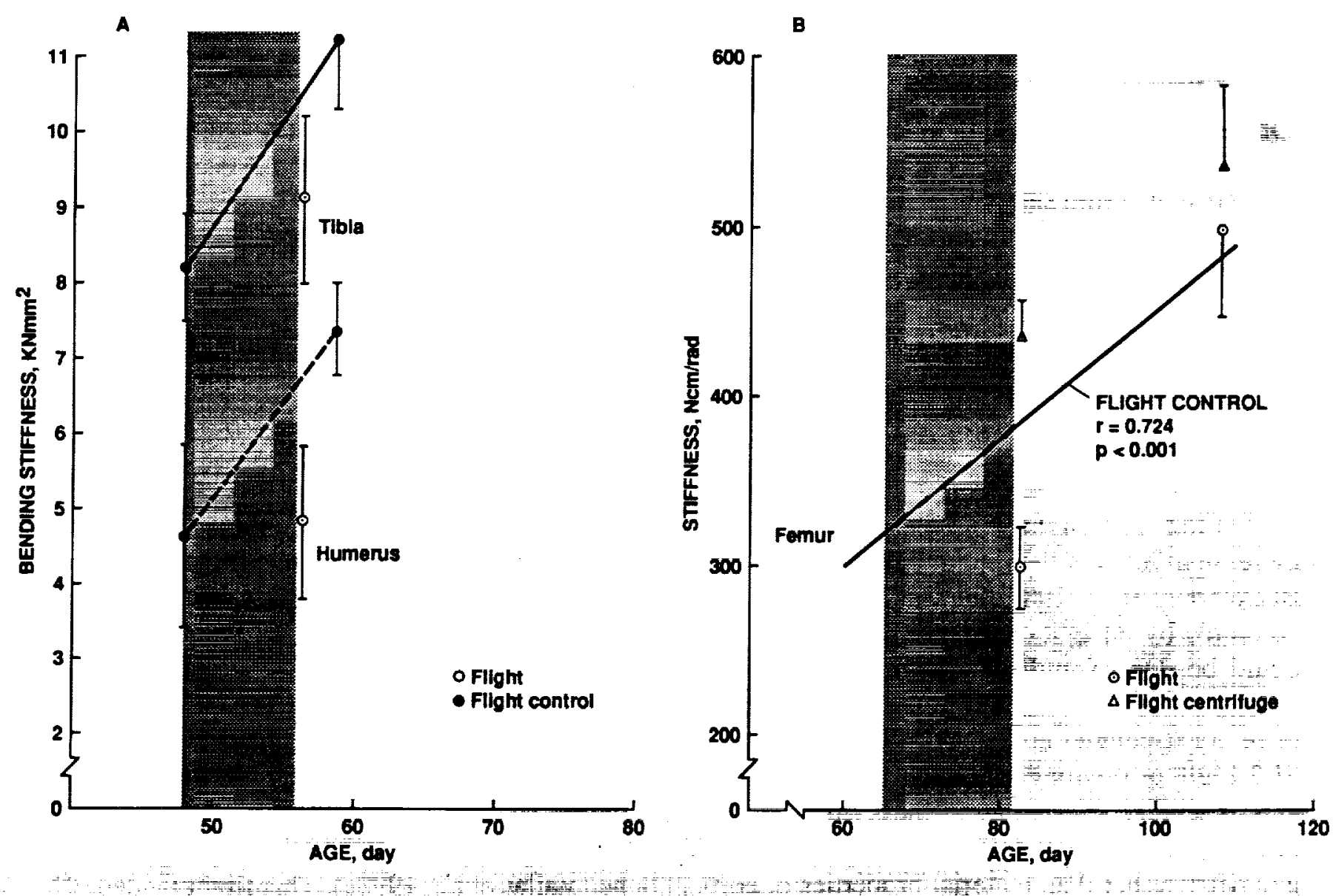

Figure 3. Effects of age and spaceflight on bending stiffness of leg bones of growing rats. Panel A compares the normal increase with age in bending stiffness of the humerus and tibia with space flight effects during Spacelab 3; panel B shows the normal increase in torsional stiffness of the fernur with age compared to spaceflight effects from Cosmos 936 and recovery following the mission as well as restoration of the normal increase with age by the use of artificial gravity in space. Shaded areas represent the flight period. Data are expressed as mean \pm SD.

A. Spacelab 3 tibia and humerus (plotted from Shaw et al., 1988). The lines connect the preflight and postflight values of control animals with the solid line representing the tibia and the dashed lines representing the humerus. The open circles represent flight rats; the lower circle is humerus and the upper circle is tibia. Flight animals did not show the increase in stiffness with age seen in the control group, but they did not lose stiffness during flight. Modulus of elasticity was also signficantly lower in the humerus.

B. Cosmos 936 femur (plotted from Spengler et al., 1983). The linear regression line was calculated from flight control values at three time points: the beginning and end of a $18.5 \mathrm{~d}$ flight and 25 days postflight; correlation between age (size) and stiffness was highly significant. The flight rats (circles) showed no increase in stiffness at the end of flight, but the defect was corrected postflight; note that the flight rats did not lose stiffness during flight. The rats centrifuged at $1 \mathrm{G}$ during flight (triangles) showed, if anything, greater stiffness than the controls at the end of the flight and the postflight period. 
TABLE 2. PERCENT OF CROSS-SECTIONAL AREA FORMED DURING FLIGHT PERIOD

FLIGHT

$782 \quad 936 \quad$ COSMOS

1129

SL3

\begin{tabular}{|c|c|c|c|c|c|c|}
\hline & 782 & 936 & 1129 & 1129 & YOUNG & ADULTS \\
\hline AGE & $63 d$ & $64 d$ & \multicolumn{2}{|c|}{$83 d$} & \multicolumn{2}{|c|}{$84 d$} \\
\hline SITE & $\begin{array}{c}\text { Tibial } \\
\text { Diaphysis }\end{array}$ & $\begin{array}{c}\text { Tibial } \\
\text { Diaphysis }\end{array}$ & $\begin{array}{c}\text { Tibial } \\
\text { Diaphysis }\end{array}$ & $\begin{array}{l}\text { Humeral } \\
\text { Diaphysis }\end{array}$ & $\begin{array}{c}\text { Tibial } \\
\text { Diaphysis }\end{array}$ & $\begin{array}{l}\text { Humeral } \\
\text { Diaphysis }\end{array}$ \\
\hline \multicolumn{7}{|l|}{ GROUP } \\
\hline Control & $12.7 \pm 0.6$ & $19.3 \pm 2.5$ & $11.7 \pm 1.8$ & $10.9 \pm 2.6$ & $5.5 \pm 1.6$ & $5.4 \pm 1.1$ \\
\hline Flight & $8.0 \pm 2.8$ & $12.0 \pm 2.2$ & $6.1 \pm 0.6$ & $7.6 \pm 1.5$ & $3.2 \pm 0.7$ & $4.9 \pm 1.0$ \\
\hline$\Delta$ & 4.7 & 7.3 & 5.6 & 3.3 & 1.7 & 0.5 \\
\hline
\end{tabular}

Cosmos 782 from data collected for Morey and Baylink, 1988.

Cosmos 936 from data collected for Morey,et al., 1978.

Cosmos 1129 from data collected for Wronski and Morey, 1983a.

SL3 from data collected for Wronski et al., 1987.

biological variability and accuracy of most chemical techniques. If differences in concentration (unit per gm of bone) are found between flight and flight controls, then the data are suggestive of changes through-out the total bone rather than solely in the bone formed during flight. Most differences in bone chemistry from space flight can be attributed to the smaller flight bones rather than changes in concentration. However, some changes in concentration have been reported. In the younger rats flown on SL3, phosphorus concentration in the proximal and distal third of the humerus (but not the middle third or vertebra) decreased and vertebral (but not humeral) hydroxyproline increased while $\mathrm{Ca}$, magnesium, osteocalcin (a non-collagenous bone matrix protein), and percent nonmineralized collagen did not change (Patterson-Buckendahl et al., 1987). Decreased accumulation of osteocalcin was more evident in the rapidly growing vertebra than in the humerus and the amount of this protein in whole-carcass powder was also reduced reflective of the decreased skeletal growth in the flight animals rather than a change in concentration. In pooled samples from four Cosmos $1887 \mathrm{flight}$ or control rats, an increase in reduced collagen cross-links, dihydroxylysinonorleucine (DHLNL) and hydroxylysinonorleucine (HLNL), and their ratio was noted in flight proximal femur diaphysis compared to control, but no change was reported in the distal diaphysis or distal end for DHLNL or in any site in the femur for HLNL and pyridinoline (nonreducible collagen cross-link). In addition, $\mathrm{Ca}$, phosphorus, and osteocalcin decreased at the distal diaphysis but no other site, while hydroxyproline (i.e., collagen) decreased only in the proximal metaphysis (Mechanic et al., 1990). These data suggest that changes in mineral and matrix composition in the whole bone are site specific.

\section{E. Maturation and Growth}

Bone maturation has been studied by means of density gradient fractionation. Bones are ground into a fine powder which is separated into different density fractions, and mineral and matrix 
components are determined in each fraction with the less dense fraction being less mature (Russell and Avioli, 1972). Delayed bone maturation was found in mandible (Simmons et al., 1983), thoracic vertebra, femur shaft and metaphysis (Simmons et al., 1986), and calvaria (Simmons et al., 1990). The lower incisor and rib did not differ from controls (Simmons et al., 1983), but their function did not change during flight. The maturation defect was expressed differently in different tissues. For example, calcium, phosphorus, and hydroxyproline increased in the the lower density fractions and decreased in the higher density fractions in 18.5 day Cosmos 1129 flight mandibles (Simmons et al., 1983). In the younger rats on the 7 day SL3 flight, the low intermediate density decreased and the high intermediate density profiles increased in the femur whereas the vertebrae had less mineral in the intermediate fractions and a shift in dry weight toward both the low and high mineral densities (Simmons et al., 1986). In the calvaria from the 12 day Cosmos 1887 mission the weight distribution pattern was similar to that of the mandibles of the Cosmos 1129 mission (Simmons et al., 1990).

Radial growth in the tibia of young adult rats (Wronski et al., 1987) and the tibia (Morey and Baylink, 1978; Morey et al., 1978; Wronski and Morey, 1983a) and humerus (Wronski and Morey, 1983a) of rapidly growing rats was about $40 \%$ slower during spaceflight. This response was very consistent in the tibiae from rats onboard the Cosmos flights lasting 18.5-19.5 days (Table 3). The vivarium and flight control groups had similar formation rates during Cosmos 782 and 936 . In Cosmos 1129 the difference between these groups probably resulted from immobilization in the flight groups since the animals, but not the cages, grew during the $20 \mathrm{~d}$ flight delay. A significant (23\%) decrement in bone mineralization rate in the humerus was also reported in flight rats on Cosmos 1129, while ribs showed a slight decrease (18\%) (Wronski and Morey, 1983a). Mineral apposition rate in the body of the mandible with contiguous muscle was not altered, while bone

\section{TABLE 3. DATA FROM COSMOS EXPERIMENTS}

COSMOS FLIGHT

FLIGHT DURATION

RAT AGE AT LAUNCH

INITIAL BODY MÄSS
782

$19.5 \mathrm{~d}$

$63 \mathrm{~d}$

$215 \mathrm{~g}$
936

$18.5 \mathrm{~d}$

$64 d$

$200 \mathrm{~g}$
1129

$18.5 \mathrm{~d}$

$83 \mathrm{~d}$

$290 \mathrm{~g}$
GROUP

$\begin{array}{lc}\text { FLIGHT CONTROL } & 15.8 \pm 1.5 \\ \text { VIVARIUM CONTROL } & 16.0 \pm 1.4 \\ \text { FLIGHT CENTRIFUGE (936 only) } \\ \text { FLIGHT } & 9.4 \pm 2.8 \\ \% \Delta \mathrm{FC} & -40 \\ \% \Delta \mathrm{V} & -41\end{array}$

PERIOSTEAL BONE MINERALIZATTIONN RATE, $\mathrm{mm}^{2} /$ day

$\% \Delta \mathrm{FCent}$ (936 only)

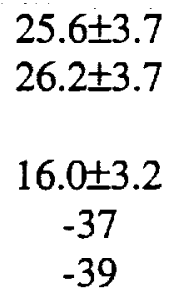

$-39$
$17.9 \pm 2.7$

$22.6 \pm 4.7$

$17.6 \pm 3.0$

$10.0 \pm 2.1$

$-44$

$-56$

Cosmos 782 data from Morey and Baylink, 1988.

Cosmos 936 data from Morey et al., 1978.

Cosmos 1129 data from Wronski et al., 1987. 
without muscle showed a 30\% decrease (Simmons et al., 1983). Variations in mineralization rate during flight can also be found within the same cross-section of a long bone. In the tibia, normal mineralization rate is highest around the posterior eminence due to muscle forces and this region was the least effected by flight $(-16 \%)$ whereas the greatest flight effect was along the anterior, medial, and lateral aspects of the tibia $(-48 \%)$ (Spector et al., 1983).

An interesting finding was the appearance of an arrest line in the cortical bone of rats allowed to recover from flight (Cosmos 782, 936, and 1129). This cement line was coincident with the periosteal surface at the end of the flight period and extended around the bone except for the posterior eminence. The arrest line was superimposed on the bone marker given 3-5 days postflight indicating a cessation of bone formation since little or no bone formed immediately postflight. This response has been noted in the tibia (Morey and Baylink, 1978; Morey et al., 1978; Wronski and Morey, 1983a ) and humerus (Wronski and Morey, 1983a). The arrest line, which appeared to be hypomineralized, was approximately $3 \mu \mathrm{m}$ wide and separated the bone formed during spaceflight from that formed following spaceflight. Bone matrix at the arrest line was abnormal; fibers (presumably collagen) were oriented parallel to the arrest line and perpendicular to the radial direction of growth. The fibers had an irregular convoluted pattern just within the line along the flight period side; no such pattern was noted in either the preflight or postflight side. The pattern suggested that cytoskeletal elements in the osteoblasts, aligned to orient collagen vesicles during secretion (Doty, 1988), were disrupted in space; this malfunction could alter the ability of collagen to form a stable structure (Turner et al., 1985a). Lack of an organized structure could partially explain the indication of smaller bone crystals in the mandible, but not calvaria, of flight rats (Simmons et al., 1986 and 1990). Smaller crystals would be not be as resistant to abrasion as normal crystals. Thus, hypomineralization could be an artifact of tissue preparation. The sparse crystals oriented their crystallographic $c$-axis along the long axis of the fibrils whereas no extensive regions of preferred orientation were observed in bone formed before or after flight (Turner et al., 1985a). Focal vascular occlusion just beneath the outer surface of cortical but not cancellous bone has been noted following flight and could contribute to localized bone changes (Doty et al., 1990). Normally mineralized pericanalicular bone in the arrest zone suggested that the defective bone was the result of abnormal matrix which did not properly mineralize.

\section{F. Cancellous Bone and Cell Populations}

Indications of decreased cancellous bone were found in the tibia, femur, and humerus on the 22d Cosmos 605 mission (Yagodovsky et al., 1976). Cancellous bone volume in the tibia and humerus was lower and marrow fat was higher in the flight rats in Cosmos 1129; analysis of bone cell populations in the proximal humerus showed a decrease in osteoblasts immediately adjacent to the growth cartilage-metaphyseal junction, but osteoclast numbers were unchanged (Jee et al., 1983). Similar changes were found in the proximal tibia of $105 \mathrm{~d}$ old male rats following the $7 \mathrm{~d}$ Cosmos 1667 flight, but no changes were noted in the femur, thoracic or lumbar vertebrae (Vico et al., 1988). Pregnant rats from the 5d Cosmos 1514 mission showed no change in trabecular bone volume in the tibia, lumbar or thoracic vertebra (Vico et al., 1987c). On SL3, young adult rats showed a suppression of formation in the tibial shaft, but histomorphometric parameters (trabecular bone volume, osteoclast surface and number, osteoblast surface and number) in the proximal humerus and lumbar vertebra were unchanged. 
Growing rat studies have focused on the biomineralization defect since most data suggest no change in osteoclastic activity (Cann and Adachi, 1983 [bone resorption kinetics]; Jee et al., 1983; Wronski et al., 1987; Vico et al., 1988; Kaplansky et al., 1987). However, indications of increased osteoclastic activity have been reported in a few sites (Kaplansky et al., 1987 [Cosmos 1667 primary spongiosa of tibia]; Vico et al., 1987c [thoracic vertebra but not lumbar vertebra or primary or secondary spongiosa of tibia in pregnant rats flown on 5d Cosmos 1514]).

\section{G. Non-weightbearing Bones}

Although one might anticipate changes in weightbearing bones, there is no a priori reason to expect alterations in non-weightbearing bones. However, changes in mineralization rates and bone tumover, maturation, and progenitor populations have been reported in the maxilla and mandible (Simmons et al., 1983; Roberts et al., 1987; Jackson et al., 1988). Precursor cells which become osteoblasts may differentiate at a slower rate in the maxilla during spaceflight (Roberts et al., 1987; Garetto et al., 1990), and fewer osteoblasts would form less bone. The mandibular condyle, which is loaded during eating but is non-weightbearing, may be exquisitely sensitive to microgravity (Jackson et al., 1988). The muscles in the jaw may contribute to these changes since the mandible would not require active muscle tone to stay closed in space and changes in these postural muscles may occur. In addition to the jaws, maturation of the calvaria was shown to be delayed during Cosmos 1887 (Simmons et al., 1990). Thus, most bone tissues seem to show a response to spaceflight and the detection of such a change appears to be dependent upon the mineralization rate of the tissue (which is related to age and function), the length of the flight, and the technique used.

\section{H. Recovery from Spaceflight}

With the exception of trabecular bone mass in the proximal tibia, all bone defects noted above appeared to recover within a month after return from space. Table 4 compares postflight recovery of tibial mineralization of flight controls with flight rats and rats centrifuged at $1 \mathrm{G}$ during Cosmos 936 (Morey et al., 1978). Half of each group of rats was euthanized immediately following flight and the remaining animals were given a bone marker four days following flight. The difference in bone area between those animals killed immediately following flight and those receiving the postflight label was calculated to provide an estimate of the amount of bone formed during the first four days postflight for each group. Both groups showed a similar suppression of mineralization during spaceflight. In the first four days following flight, the total amount of bone formed by the flight rats was formed by control rats in $0.8 \mathrm{~d}$ suggesting a lag time of approximately $3.2 \mathrm{~d}$ before the flight rats began to form bone postflight. On the other hand, the total amount of bone formed by the flight centrifuged rats in the first four days following flight was slightly greater than that formed by the controls suggesting an immediate recovery of formation in the centrifuged rats. In addition, the arrest line was significantly longer in the flight rats than either the flight centrifuged animals or the flight controls.

\section{Interpretation}

Data from Cosmos 936 are particularly important in interpreting the skeletal response of growing rats to spaceflight due to the onboard $1 \mathrm{G}$ centrifuge control. The arrest line and the apparent lag time 
TABLE 4. RAT TIBIA MINERALIZATION ON COSMOS 936

Number of specimens

Bone area $\left(\mathrm{mm}^{2}\right)$ formed in 4 days immediately postflight

Time (d) required for controls to form bone area formed by flight groups

Mineralization Rate $\left(\mathrm{mm}^{2} / \mathrm{d}\right)$

$\% \Delta$ flight control

$\mathrm{p}$ vs flight control

Length of Arrest Line (mm)

$\% \Delta$ flight control

p vs flight control
FLIGHT

5

$0.04 \pm 0.07$

0.8
$0.01 \pm 0.02$
$-61$
$<0.1$

$4.0 \pm 1.1$

$+250$

$<0.005$
FLIGHT CENTRIFUGE

5

$0.12 \pm 0.06$

4.7

$0.03 \pm 0.02$

$+17$

n.s.

$2.3 \pm 0.4$

$+144$

$<0.05$

Data from Morey et al., 1978.

for reinitiating bone formation in the flight rats suggest a cessation of formation which would necessitate stimulation of progenitor populations to recover from the defect. The rapid recovery in centrifuged animals suggests that mineralization decreased rather than ceased and the decrease may have been due to reduced activity of the animals in the fixed cage, short-radius, high rotation rate centrifuge. Both flight groups formed the same amount of bone at the periosteal surface during flight and had the same bone mass, density, and presumably geometry, yet stiffness was very different (Spengler et al., 1983). Thus, the changes in stiffness during spaceflight (Spengler et al., 1983; Shaw et al., 1988) cannot be totally explained by changes in geometry or density and implicate other alterations in material properties. These studies also imply that techniques measuring solely bone mass or bone density could significantly underestimate the change in bone biomechanical properties during spaceflight.

The degree of skeletal change during flight depended on the rate of growth and the site in the bone. For example, the younger animals on the 7-day SL3 mission exhibited significant bone changes, while older animals exhibited only similar trends in many bone parameters. Yet all animals on the 19-day flights showed significant differences whether 63 or 83 days old (Table 2). Regardless of flight duration, the young animals showed negligible signs of bone loss. Some components of bone continued to grow, while other features suggested growth suppression or arrest of biomineralization. 
The site(s) of the biomineralization defect during spaceflight are not know, but alterations in bone matrix could alter crystal size and impede increases in bone strength. The duration and extent of the skeletal changes in growing rats during spaceflight have not been defined.

\section{GROUND-BASED UNLOADING-INDUCED SKELETAL CHANGES IN GROWING RATS.}

\section{A. General}

In 1975 when the Cosmos cooperation between the US and USSR started, we began development of a ground-based rat model to simulate some effects of spaceflight. Animal models for skeletal disuse did exist, but the disuse was produced by decreased activity due to confinement in a small cage, flacid paralysis due to nerve-section, or unloading through surgical tenotomy. None of the techniques produced a differential muscle atrophy which primarily affected the postural or weight-bearing muscles as was noted during spaceflight. Surgical procedures induced a regional acceleratory phenomena which led to initial, rapid bone loss and the procedures could not be reversed. Thus, existing models were not appropriate to study the response to and recovery from spaceflight. The main criteria for development of an acceptable model simulating spaceflight in growing rats were 1) differential muscle atrophy, 2) a headward fluid shift, 3) the ability to move, eat, and groom normally using the front paws, 4) unloading of the rear limbs without paralysis so that the animals could be reloaded and recovery from unloading effects observed, 5) weight gain throughout the experimental period, and 6) validation using spaceflight data. Such a model would be invaluable in predicting spaceflight effects on musculoskeletal growth and development, studying potential mechanisms, and establishing a time course of responses, and would be less expensive and more accessible than spaceflight. Many ideas for a rat model were generated and some were tested. The system from which data were initially published used an orthopedic casting material bonded to the back of the rat (Morey, 1979). A wire thread was incorporated into the harness and the wire was attached to a freely rotating fishline swivel on an overhanging horizontal aluminum beam. The beam was fixed to a post by a ball bearing rotating in a horizontal plane. The animals were attached at about a $30^{\circ}$ head-down angle so that the rear limbs did not bear weight. The animals could move freely about a $360^{\circ}$ arc because the forelimbs were allowed to touch the plexiglass grid floor. Many synonyms have been used to describe rats on this model system including ground-based flight simulation, flight model or model, suspended, hinquarters unloaded, partially unloaded hindlimb elevation, unweighted, tail-traction, intact unloading (vs surgically-induced), and disuse. In this document, suspended is used to describe the rat model while unloaded is used to describe skeletal status.

Some bone responses to unloading using the back harness appeared to be similar to those noted in space (decreased periosteal mineralization in the tibia, reduced cancellous bone with increased marrow fat, decreased osteoblast numbers, recovery within two weeks of reloading after two weeks of suspension), but some responses were different (increased osteoclastic numbers in the tibia and humerus and failure to gain weight). Additionally, a decrease in the rate of longitudinal bone growth in both tibia and humerus was reported (Wronski and Morey, 1982, 1983b). Unfortunately, the suspended animals did not gain weight while controls grew, and the harness had to be rebonded at about two-week intervals. The lack of weight gain using this hamess system implied a stressful situation which could inhibit bone growth. To minimize discomfort to the young male rats, the harness device was changed first to a plaster of Paris cast at the base of the tail (Morey-Holton and 
Wronski, 1981) and finally to orthopedic traction tape along the tail (Wronski and Morey-Holton, 1987). The head-down angle, suspension of the hindquarters, the cephalad fluid shifts, and the use of the forelimbs for locomotion remained the same but the overhead beam was changed to an X-Y pulley system which allowed the animal free movement throughout the cage. The tail-traction system fulfilled most of the criteria for an adequate model system and evolved into the technique of choice for studying bone changes mimicking spaceflight in growing rats. The tail-traction system rather than the back harness or body harness (Musacchia et al., 1980) is better for developmental studies because rats gain weight similar to controls when controls are fed daily the mean food consumption of the experimental rats. If one wants to study growth and development, then the animals must grow; if growth is inhibited in experimental animals while the controls continue to grow, then differentiating between the effects of growth retardation and the effects of unloading on the skeleton is difficult, if not impossible.

\section{B. Serum Parameters}

The initial period of inhibited bone formation during skeletal unloading was marked by a small but significant increase $(-10 \%)$ in the serum concentration of $\mathrm{Ca}$, a dramatic decrease $(60 \%)$ in the serum concentration of 1,25 -dihydroxyvitaminD $\left(1,25(\mathrm{OH})_{2} \mathrm{D}\right)$, a small and insignificant increase in the serum of 24,25 -dihydroxyvitaminD $\left(24,25(\mathrm{OH})_{2} \mathrm{D}\right)$, and no change in the serum concentration of 25-hydroxyvitaminD (25-OHD)(Halloran et al., 1986). Between days 5-15 of suspension, the serum concentrations of $\mathrm{Ca}, 1,25(\mathrm{OH})_{2} \mathrm{D}$ and $24,25(\mathrm{OH})_{2} \mathrm{D}$ all returned to normal and presumably remained so indefinitely, although measurements in animals suspended for periods longer than 15 days were not made (Halloran et al., 1986). The bone changes still occurred when the transitory fall in serum $1,25(\mathrm{OH})_{2} \mathrm{D}$ was prevented by continuous infusion of $1,25(\mathrm{OH})_{2} \mathrm{D}$ (Halloran et al., 1986), or when the serum concentrations of $1,25(\mathrm{OH}) 2 \mathrm{D}$ were manipulated by changing dietary $\mathrm{Ca}$ (Globus et al., 1986a). These facts suggest that the transitory decrease in serum $1,25(\mathrm{OH})_{2} \mathrm{D}$ associated with acute skeletal unloading was probably not the cause of the defect in bone formation, but rather the result of changes in bone cell activity and demand for $\mathrm{Ca}$. It is important to note that increasing dietary $\mathrm{Ca}$ did not prevent the decreased bone growth induced by suspension, but it did increase bone $\mathrm{Ca}$ and thereby provided some protection against unloading (Globus et al., 1986a).

The serum concentration of parathyroid hormone (PTH) was normal after 15 days of skeletal unloading (Globus et al., 1986a) as were the serum concentrations of $\mathrm{Ca}$, inorganic phosphate, $1,25(\mathrm{OH})_{2} \mathrm{D}, 24,25(\mathrm{OH})_{2} \mathrm{D}, 25-\mathrm{OHD}$. Osteocalcin decreased in serum within five days of

suspension, but returned to normal within 15 days reflecting changes in bone growth (PattersonBuckendahl et al., 1989).

To determine if glucocorticoids, potent inhibitors of bone formation, might be involved in the suppressed bone mineralization, adrenalectomized rats were suspended. Also, the circadian periodicity of glucocorticoids was measured in intact rats following suspension. The results suggested that the response was not due to increased plasma glucocorticoids or an increase in bone sensitivity to the glucocorticoids (Halloran et al., 1988). 


\section{Biomechanics}

A study investigating femur biomechanical properties in young rats suspended for one, two, or three weeks used a modification of the back harness and reported altered geometric and material properties compared to controls (Abram et al., 1988). Most parameters continued to decrease with time of suspension, but the changes may have been due to failure of the suspended rats to grow normally. Using the tail harness to suspend young, female rats for four weeks, Shaw et al (1987) reported that the only cross-sectional morphology change was the anterior cortical thickness of the femur. All mechanical characteristics were decreased in the femur but only bending stiffness was altered in the tibia. Vailas et al. (1990b) reported that young male rats suspended for two weeks showed decreased mechanical properties of the femur/tibia medial collateral ligament while crosssectional area of the tissue did not change. These studies suggest that suspending the hindquarters induced changes in mechanical properties of tibia, femur, tendons, and ligaments.

\section{Chemical Composition}

Ca concentration of multiple bones at different time periods was not affected by suspension. Shaw et al (1987) reported that tibia and femur concentrations of collagen, phosphorus, and $\mathrm{Ca}$ in suspended rats did not differ from controls. Vailas et al. (1988) reported no differences between suspended and control rats in femur concentration of $\mathrm{Ca}$, phosphorus, DNA, hydroxyproline, or uronic acid. However, hydroxyproline and uronic acid, but not DNA, were significantly lower in the suspended patellar tendon. Changes in osteocalcin and $\mathrm{Ca}$ in the lumbar vertebra and femoral diaphysis with time of suspension paralleled the changes in bone weight and few changes in concentration were found (Patterson-Buckendahl et al., 1989). Total bone Ca in tibia and lumbar vertebra decreased $10-40 \%$ within one week of unloading and remained supressed until reloaded, reflecting the smaller bones in the suspended rats (Globus et al., 1986b; Halloran et al., 1986).

\section{E. Metabolism, Maturation, and Growth}

Bone metabolism changed during suspension. Unloaded bones (tibia, femur, and lumbar vertebra) showed decreased metabolism, while metabolism in loaded bones (mandible, humerus, or cervical vertebra) did not change (Globus et al., 1984; Globus et al., 1986b). Within 5-7 days of suspension, a significant inhibition of Ca metabolism and collagen production (as indicated by [ $\left.{ }^{45} \mathrm{Ca}\right]$ and $\left[{ }^{3} \mathrm{H}\right]$-proline uptake) occurred in unloaded bones. Between days 7-15 of suspension, uptake of $\left[{ }^{45} \mathrm{Ca}\right]$ and $\left[{ }^{3} \mathrm{H}\right]$-proline returned to normal. Retarded mineralization resulted in a decrease in mature bone; the effects were maximal in young, male rats after 10 days of suspension, then returned toward control values (Bikle et al., 1987).

Bone formation rate at the tibiofibular junction was reduced by $50 \%$ within one week of suspension (Globus et al., 1986b) . Between days 7-15 of suspension, bone formation rate at the tibiofibular junction returned toward normal, but was still significantly suppressed at the end of two weeks. Tibial longitudinal bone growth was reduced by $21 \%$ within 5 days (Halloran et al., 1986), but retumed to normal within two weeks (Wronski and Morey, 1987). Vailas et al. (1988) reported no differences between suspended and control rats in femur length or weight and cortical or endosteal parameters (area, circumference, density, maximum diameter), but did find an increase in minimum diameter in the suspended group. In another experiment, rats were suspended for 14, 30, 
60 , or 90 days (LeBlanc et al., 1985). Technetium-labeled methylene diphosphonate uptake (normalized to Ca concentration) in tibia, femur, and humerus indicated a suppression of formation in the two-week suspended group with indications of increased uptake in the femur at $60 \mathrm{~d}$. Regional densitometry of the femur showed progressively less bone mineral compared to controls beginning with cancellous bone at 30 days and extending to the shaft by 60 days with the defect being similar in magnitude in both regions by 90 days of suspension. Regional blood distribution did not change in any long bone, but did change in muscle. Although no difference in any bone length was noted, decreases in femur total width, medullary canal width, and cortical thickness were noted at $90 \mathrm{~d}$. No morphometric evidence was found for an increased medullary resorption rate in the bone shaft.

\section{F. Cancellous bone and cell populations}

Trabecular bone surface lined with osteoblasts was reduced by $32 \%$, but percent bone surface lined with osteoclasts was unchanged within 5 days of suspension (Halloran et al., 1986). The osteoblast population returned to normal within two weeks of continued suspension (Wronski and Morey, 1987). Osteoclastic activity appeared elevated by $60 \mathrm{~d}$ in the metaphyseal region of the femur suggesting increased turnover in this bone (LeBlanc et al., 1985).

\section{G. Bone Mass Redistribution}

A recent three-week study using weanling rats showed a redistribution of bone mass during suspension with a decrease in the femur and tibia, a moderate increase in the humerus and radius/ulna, and a significant increase in the skull and mandible, and implicates fluid shifts in the response (Roer and Dillaman, 1990). A similar finding has been reported in bed-rested human subjects (LeBlanc et al., 1990).

\section{H. Recovery from Suspension}

If animals were reloaded after two weeks of suspension, recovery of the bone mass deficit and strength appeared to require somewhat more than two weeks (Sessions et al., 1989; Abram et al., 1988). These data are consistent with the hypothesis that skeletal unloading in growing animal produces inhibition of bone formation. With time and continued suspension, bone metabolism and growth return toward normal. Total bone mass remains low because of the initial reduction in bone formation and subtle defects in mineralization (Bikle et al., 1987). Recovery of the defect required longer for some bone parameters than others.

\section{Comparison with Flight Data}

Simulation of Cosmos 1667 suggested that $7 \mathrm{~d}$ of suspension decreased tibial metaphyseal bone less in suspended than in flight rats. No change was noted in flight femoral trabecular bone measured under muscular insertions, but a reduction was noted in suspended rats. Vertebral bodies were not affected by flight but suspended rats showed a trend of decreasing mass (Vico et al, 1987a). Tumer (1985b) compared bone mineralization in anterior, posterior, medial, and lateral aspects of tibial cross-sections in flight (19d), suspended (14d), and nerve-sectioned (21d) rats and found a greater inhibition of mineralization at all sites in flight rats. Simulation of SL3 reported hindlimb muscle 
atrophy (Morey-Holton et al., 1988) and decreased femoral bone biomechanics (Martin et al., 1988) similar to spaceflight; unlike spaceflight, humeral parameters did not change .

\section{J. Interpretation}

The rat model has proved invaluable, particularly in predicting the early response to spaceflight. Data from the first week of suspension, whether on Earth or in space, are similar. However, bone metabolism and mineralization appear to return to normal levels with continued suspension on Earth while spaceflight may require longer for stabilization of bone parameters. A spaceflight defect which has not yet been reproduced in ground-based studies is the arrest line in cortical bone. Total skeletal unloading occurs during flight, but only partial unloading is possible in the ground model as the humerus and cervical vertebra continue to bear some weight. In fact, the humerus serves as an internal control for the ground experiments (results should be the same in humerus of suspended and control groups) but this bone does change during spaceflight. Also, the stress of reentry, and the time delay between reentry (with reloading) and sampling of flight specimens, can create difficulty in comparing data with model experiments where animals are sampled while still suspended. The model has also been used to study the time course of changes in bone and the endocrine status at the end of the suspension period which has not been possible on a single Space Shuttle mission or unmanned flight.

\section{CONCLUSION AND SUMMARY}

Observations in adult humans and juvenile animals during and after spaceflight have provided us with basic concepts regarding the role of gravity in the determination of bone structure. The response of the skeleton to a new environment that imposes different biomechanical stresses is complicated by its dual function as a support structure and as a mineral reservoir. The transport of the minerals is regulated and influenced by organ systems (i.e. cardiovascular, muscular, renal, gastrointestinal) whose anatomy and metabolism are also affected by microgravity. This review deals almost exclusively with the observed and potential effects of spaceflight on bone, but some findings are cited from other body systems where spaceflight seems to have a major impact on the adaptation of bone to microgravity.

The primary site of the response of bone tissue to microgravity is at the interface of mineral and matrix in the process of biomineralization. This is manifested in the adult by demineralization of some regions of the skeleton. The most pronounced effects are seen in os calcis, the most distally located bone relative to the heart. In-flight biochemical and endocrine studies from the Skylab missions, primarily, suggest an hypothetical scheme for the pathogenesis of the two major consequences of space flight, negative calcium balance and demineralization. The extent of these effects varies greatly between individual astronauts and cosmonauts. Diet, glucocorticoid excess, and activity level prior to and during spaceflight are influences that may account for the variation in density of bones measured. While quantitative losses of mineral from the whole skeleton are relatively small, regional or localized areas of demineralization during spaceflight could seriously impair the support function of the skeleton on return to Earth.

In depth study of the biomechanics, morphology, chemistry and development of young rat bones have revealed the highly selective and regional nature of the response of bone structure to 
spaceflight. There is either depressed or arrested maturation of new bone. There is also a decrease in strength compared to controls, which may be related to the failure of mineralization and to an impaired differentiation of bone forming cells. However, from observation of animals maintained at artificial gravity during spaceflight, we have learned that other elements in the composition and structure of bone, independent of mineral content, geometry, and growth rates, are important for bone strength.

A ground-based flight simulation model for extended study of bone structure at the molecular, organ and whole body levels is described and compared to the flight results. On Earth, the morphologic and compositional changes in the unloaded bones are very similar to changes in flight; however, the ground-based changes appear to be more transient than those reported during spaceflight. In addition, there is a redistribution of bone mineral to gravity dependent bones of the model. Longitudinal data have provided considerable information on the influence of endocrine and muscular changes on bone structure following unloading.

These investigations have defined important areas of future investigation for resolving basic biology and biomedical questions on the mechanism of structural adaptation of the skeleton to a new environment. There is clearly a need for more interdisciplinary physiological studies. Basic questions regarding the mechanism of revision of bone architecture are likely to be answered by integrated work in muscle and bone that is directed to uncovering the signals for local cell activity and a better knowledge of the molecular structure of bone and its regulation. 


\section{REFERENCES}

Abram, A. C., T. S. Keller, and D. M. Spengler. The effects of simulated weightlessness on bone biomechanical and biochemical properties in the maturing rat. J. Biomechanics. 21: 755-767, 1988.

Aranow, M. A., L. C. Gerstenfeld, T. A. Owen, M. S. Tassinari, G. S. Stein, and J. B. Lian. Factors that promote progressive development of the osteoblast phenotype in cultured fetal rat calvaria cells. J. Cell Physiol. 143: 213-221, 1990.

Arnaud, S. B. and E. Morey-Holton. Gravity, calcium, and bone: Update, 1989. The Physiologist. 33: S65-67, 1990.

Amaud, S. B., Powell, M. R., Whalen, R. T. and Vernikos-Danellis, J. Bone mineral redistribution during head down tilt bed rest. Am. Soc. Gravit. Space Biol. Bull. 2: 54, 1989.

Arnaud, S. B., V. S. Schneider, and E. Morey-Holton. Effects of inactivity on bone and calcium metabolism. In:Inactivity: Physiological Effects, H. Sandler and J. Vernikos, eds., Academic Press, Inc. Orlando, FL, 1986, pp. 49-76.

Baron, R. Anatomy and ultrastructure of bone. In: Primer on the Metabolic Bone Diseases and Disorders of Mineral Metabolism, M. J. Favus, ed., Am. Soc. Bone Mineral Res., Kelseyville, CA, First Edition, 1990, pp. 3-7.

Bikle, D. D., B. P. Halloran, C. C. Cone, R. K. Globus, and E. Morey-Holton. The effects of simulated weightlessness on bone maturation. Endocrinology. 120: 678-684, 1987.

Binderman, I., Z. Shimshoni, and D. Somjen. Biochemical pathways involved in the translation of physical stimulus into biological message. Calcif. Tissue Int. 36: S82-S85, 1984.

Buckley, M. J., A. J. Banes, L. G. Levin, B. E. Sumpio, M. Sato, R. Jordan, J. Gilbert, G. W. Link and T. S. Tay. Osteoblasts increase their rate of division and align in response to cyclic, mechanical tension in vitro. Bone Mineral 4: 225-235, 1988.

Canalis, E. Regulation of bone remodeling. In: Primer on the Metabolic Bone Diseases and Disorders of Mineral Metabolism, M. J. Favus, ed., Am. Soc. Bone Mineral Res., Kelseyville, CA, First Edition, 1990, pp. 23-26.

Cann, C. E. and R. R. Adachi. Bone resorption and mineral excretion in rats during spaceflight. Am. J. Physiol. 244: R327-331, 1983.

Claus-Walker, J., J. Singh, C. S. Leach, D. V. Hatton, C. W. Hubert, and N. DiFerrante. The urinary excretion of collagen degradation products by quadriplegic patients and during weightlessness. J. Bone Joint Surgery. 59A: 209-212, 1977. 
Dalen, N. and B. Jacobson. Bone mineral assay: choice of measuring sites.Invest. Radiol. 9: 174-185, 1974.

Doty, S. B., E. R. Morey-Holton, G. N. Durnova, and A. S. Kaplansky. Cosmos 1887: morphology, histochemistry, and vasculature of the growing rat tibia. FASEB J. 4: 16-23, 1990.

Doty, S. B. The role of the cytoskeleton in bone matrix formation. ASGSB Bull. 1: 41,1988

Eanes, E. D. Physico-chemical principles of biomineralization. In: Bone Regulatory Factors; Morphology, Biochemistry, Physiology, and Pharmacology, A. Pecile and B. deBernard, Eds., NATO ASI Series A: Life Sciences, Plenum Press, NY, Vol.184, 1989, pp.1-13.

Erickson, C. Electrical properites of bone. In:The Biochemistry and Physiology of Bone, G. H. Bourne, ed. Academic Press, NY, vol. 4, 1976, pp. 329-384.

Frost, H. M. Skeletal structural adaptations to mechanical usage (SATMU): 1. Redefining Wolff's Law: The bone modeling problem. Anatomical Rec. 226: 403-413, 1990.

Frost, H. M. Skeletal structural adaptations to mechanical usage (SATMU): 2. Redefining Wolff's Law: The remodeling problem. Anatomical Rec. 226: 414-422, 1990.

Frost, H. M. Skeletal structural adaptations to mechanical usage (SATMU): 3. Redefining Wolff's Law: The hyaline cartilage modeling problem. Anatomical Rec. 226: 423-432, 1990.

Frost, H. M. Skeletal structural adaptations to mechanical usage (SATMU): 4. Redefining Wolff's Law: Mechanical influences on intact fibrous tissues. Anatomical Rec. 226: 433-439, 1990.

Garetto, L. P., M. R. Gonsalves, E. R. Morey, G. Durnova, and W. E. Roberts. Preosteoblast production 55 hours after a 12.5-day spaceflight on Cosmos 1887. FASEB J. 4: 24-38, 1990.

Gerstenfeld, L. C., S. D. Chipman, C. M. Kelly, K. J. Hodgens, D. D. Lee, and W. J. Landis. Collagen expression, ultrastructural assembly, and mineralization in cultures of chicken embryo osteoblasts. J. Cell Biol. 106: 979-989, 1988.

Globus, R. K., D. D. Bikle, and E. R. Morey-Holton. Effects of simulated weightlessness on bone mineral metabolism. Endocrinology 114: 2264-2270, 1984.

Globus, R. K., D. D. Bikle, and E. R. Morey-Holton. The temporal response of bone to unloading. Endocrinology 118: 733-742,1986b.

Globus, R. K., D. D. Bikle, B. Halloran, and E. Morey-Holton. Skeletal response to dietary calcium in a rat model simulating weightlessness. J. Bone Mineral Res. 1: 191-197, 1986a.

Grigoriev, A. I., B. R. Dorokhova, G. S. Arzamasov, and B. V. Morukov. Ion regulatory function of the kidneys in long duration space flights and simulation studies. Space Biol. and Med. 16: (1) 29-33, 1982. 
Gross, D. and W. S. Williams. Streaming potential and the electromechanical response of physiologically-moist bone. J. Biomech. 15: 277-295, 1982.

Halloran, B. P., D. D. Bikle, C. M. Cone, and E. Morey-Holton. Glucocorticoids and the inhibition of bone formation induced by skeletal unloading. Am. J. Physiol. 255: E875-879, 1988.

Halloran, B. P., D. D. Bikle, T. J. Wronski, R. K. Globus, M. J. Levens, and E. Morey-Holton. The role of 1,25-dihyroxyvitamin $\mathrm{D}$ in the inhibition of bone formation induced by skeletal unloading. Endocrinology 118: 948-954, 1986.

Harper, A. E. Recommended dietary allowances, 1980. Nutrition Rev. 38: 290-294, 1980.

Hasegawa, S., S. Sato, S. Saito, Y. Suzuki and D. Brunette. Mechanical stretching increases the number of cultured bone cells synthesizing DNA and alters their pattern of protein synthesis.Calcif. Tissue Int. 37: 431-436, 1985.

Jackson, C. B., W. E. Roberts, and E. R. Morey. Growth alterations of the mandibular condyle in Spacelab-3 rats. ASGSB Bulletin 1: 33, 1988 (Abstract).

Jee, W. S. S., T. J. Wronski, E. R. Morey, and D. B. Kimmel. Effects of spaceflight on trabecular bone in rats. Am. J. Physiol. 244: R310-R314, 1983.

Johnston. R. S. and L. F. Dietlein, eds.Biomedical Results from Skylab, NASA SP-377, Washington, DC, 1977, pp. 491.

Kaplansky, A. S., G. N. Durnova, Z. F. Sakharova, and Y. I. Myina-Kakuyeva. Histomorphometric analysis of rat bones after spaceflight aboard Cosmos-1667 biosatellite. Space Biol. Med. 21: 33-40, 1987.

Klein-Nulend, J., J. P. Veldhuijzen, M. deJong, and E. H. Burger. Increased bone formation and decreased bone resorption in fetal mouse calvaria as a result of intermittent compressive force in vitro. Bone Mineral. 2: 441-448, 1987.

Leach, C. S. and P. C. Rambaut. Biochemical responses of the Skylab crewmen: an overview. In:Biomedical Results from Skylab, R. S. Johnston and L. F. Dietlein, eds., NASA SP-377, Washington, DC, 1977, pp. 204-216.

LeBlanc, A., E. Marsh, H. Evans, P. Johnson, V. Schneider, and S. Jhingran. Bone and muscle atrophy with suspension of the rat. J. Appl. Physiol. 58: 1669-1675, 1985.

LeBlanc, A., Schneider, V., Krebs, J., Evans, H., Jhingran, S. and Johnson, P. Spinal bone mineral after five weeks of bed rest. Calcif. Tissue Int. 41: 259-261, 1987.

LeBlanc, A. D., V. S. Schneider, H. J. Evans, D. A. Engelbretson, and J. M. Krebs. Bone mineral loss and recovery after 17 weeks of bed rest. J. Bone Mineral Res. 5: 843-850, 1990. 
Lowenstam, H. A. and S. Weiner.On Biomineralization. Oxford University Press, New York, NY, 1989, pp. 25-49.

Martin, R. B., E. R. Morey-Holton, N. A. Sharkey, and A. C. Maese. Spacelab 3 simulation: bone strength study. ASGSB Bulletin. 1: 38, 1988.

Mechanic, G. L., S. B. Arnaud, A. B. Boyde, T. G. Bromage, P. Buckendahl, J. C. Elliott, E. P. Katz, and G. N. Durnova. Regional distribution of mineral and matrix in the femurs of rats flown on Cosmos 1887 biosatellite. FASEB J. 4: 34-40, 1990.

Morey, E. R. Space flight and bone turnover: correlation with a new rat model of weightlessness. BioScience 29: 168-172, 1979.

Morey, E. R. and D. J. Baylink. Inhibition of bone formation during spaceflight.Science 201: 1138-1141, 1978.

Morey, E. R., R. D. Turner, and D. J. Baylink. Quantitative Analysis of Selected Bone Parameters. In: Final Reports of U.S. Experiments Flown on the Soviet Satellite Cosmos 936, S. N. Rosenzweig and K. A. Souza, eds., NASA TM 78526, Moffett Field, CA, 1978, pp. 135-178

Morey-Holton, E. R., A. C. Maese, L. M. Kraft, and T. N. Fast. Spacelab 3 simulation. ASGSB Bulletin. 1: 38, 1988.

Morey-Holton, E. R., and T. J. Wronski. Animal models simulating weightlessness. The Physiologist 24: S45-S48, 1981.

Morey-Holton, E. R., H. K. Schnoes, H. F. DeLuca, et al. Vitamin D metabolites and bioactive parathyroid hormone levels during Spacelab 2. Aviat. Space Environ. Med. 59: 1038-1041, 1988.

Musacchia, X. J., D. R. Deavers, G. A. Meininger, and T. P. Davis. A model for hypokinesia: effects on muscle atrophy in the rat. J. Appl. Physiol. 48: 479-486, 1980.

Nicogossian, A. E., C. L. Huntoon, and S. L. Pool, eds.Space Physiology and Medicine, Lea and Febiger, Philadelphia, PA, Second edition, 1989, pp. 401.

Nogami, H. and A. Oohira. Defective association between collagen fibrils and proteoglycans in fragile bone of osteogenesis imperfecta. Clin. Orthopaed. Rel. Res. 232: 284-291, 1988.

Oganov, V. S., C. Cann, A. S. Rakhmanov, and S. K. Ternovoy. A computer tomographic investigation of the musculoskeletal system of the spine in humans after long-term space flight. Space Biol. Med. 24(4) 20-21, 1990 (Translated in USSR Space Life Sciences Digest, Issue 29, pp. 76-78, 1991). 
Owen, T. A., M. Aronow, V. Shalhoub, L. M. Barone, L. Wilming, M. S. Tassinari, M. B. Kennedy, S. Pockwinse, J. B. Lian, and G. S. Stein. Progressive development of the rat osteoblast phenotype in vitro: reciprocal relationships in expression of genes associated with osteoblast proliferation and differentiation during formation of the bone extracellular matrix. J. Cell. Physiol. 143: 420-430, 1990.

Ozawa, H., K. Imamura, E. Abe, N. Takahashi, T. Hiraide, Y. Shibasaki, T. Fukuhara, and T. Suda. Effect of a continuously applied compressive pressure on mouse osteoblast-like cells (MC3T3-E1) in vitro. J. Cell. Physiol. 142: 177-185, 1990.

Parfitt, A. M. Bone effects of space flight: analysis by quantum concept of bone remodelling.Acta Astronautica 8 (9-10): 1083-1090, 1981.

Patterson-Buckendahl, P., R. K. Globus, D. D. Bikle, C. E. Cann, and E. Morey-Holton. The effects of simulated weightlessness on rat osteocalcin and bone calcium concentrations. Am. J. Physiol. 257: R1103-1109, 1989.

Patterson-Buckendahl, P., R. E. Grindeland, R. B. Martin, C. E. Cann and S. B. Amaud. Osteocalcin as an indicator of bone metabolism during spaceflight.The Physiologist 28: S227-228, 1985.

Patterson-Buckendahl, P., S. B. Arnaud, G. L. Mechanic, R. B. Martin, R. E. Grindeland, and C. E. Cann. Fragility and composition of growing rat bone after one week in spaceflight. Am. J. Physiol. 252: R240-246, 1987.

Pollack, S. R., R. Salzstein, and D. Pienkowski. The electric double layer in bone and its influence on stress-generated potentials. Calcif. Tissue Int. 36: S77-S81, 1984.

Prokhonchikov, A. A., N. A. Zhizina, and V. Tigmayan. Homeostasis of bone tissue under normal and extreme action. In: Problems in Space Biology, ed., P. D. Gorizontov, Nauka Press, Moscow, 1984, pp. 152-165. (English translation NASA TM 77614).

Puzas, J. E. The osteoblast. In: Primer on the Metabolic Bone Diseases and Disorders of Mineral Metabolism, M. J. Favus, ed., Am. Soc. Bone Mineral Res., Kelseyville, CA, First Edition, 1990, pp. 11-15.

Raisz, L. G. Local and systemic factors in the pathogenesis of osteoporosis. New England J. Med. 318: $818-828,1988$.

Rambaut, P. C. and R. S. Johnston. Prolonged weightlessness and calcium loss in man. Acta Astronautica 4: 1113-1122, 1979.

Reich, K. M., C. V. Gay and J. A. Frangos. Fluid shear stress as a mediator of osteoblast cyclic adenosine monophosphate production. J. Cell. Physiol. 143:100-104, 1990.

Roberts, W. E. and E. R. Morey. Proliferation and differentiation sequence of osteoblast histogenesis under physiological conditions in rat periodontal ligament. Am. J. Anat. 174: 105-118, 1985. 
Roberts, W. E., P. J. Fielder, L. M. L. Rosenoer, A. C. Maese, M. R. Gonsalves, and E. R. Morey. Nuclear morphometric analysis of osteoblast precursor cells in periodontal ligament, SL-3 rats. Am. J. Physiol. 252: R247-R251, 1987.

Roer, R. D. and R. M. Dillaman. Bone growth and calcium balance during simulated weightlessness in the rat. J. Appl. Physiol. 68: 13-20, 1990.

Russell, J. E. and L. V. Avioli. Effect of experimental chronic renal insufficiency on bone mineral and collagen maturation. J. Clin. Invest. 51: 3072-3079, 1972.

Sessions, N. D., B. P. Halloran, D. D. Bikle, T. J. Wronski, C. M. Cone, and E. Morey-Holton. Bone response to normal weightbearing after a period of skeletal unloading. Am. J. Physiol. 257: E606-610, 1989.

Shaw, S. R., A. C. Vailas, R. E. Grindeland, and R. F. Zernicke. Effects of a 1-wk spaceflight on morphological and mechanical properties of growing bone. Am. J. Physiol. 254: R78-83, 1988.

Shaw, S. R., R. F. Zernicke, A. C. Vailas, D. DeLuna, D. B. Thomason, and K. M. Baldwin. Mechanical, morphological and biochemical adaptations of bone and muscle to hindlimb suspension and exercise. J. Biomechanics 20: 225-234, 1987.

Simmons, D. J., J. E. Russell, and M. D. Grynpas. Bone maturation and quality of bone mineral in rats flown on the Space Shuttle "Spacelab-3 mission". Bone Mineral 1: 485-493, 1986.

Simmons, D. J., M. D. Grynpas, and G. D. Rosenberg. Maturation of bone and dentin matrices in rats flown on the Soviet biosatellite Cosmos 1887. FASEB J. 4: 29-33, 1990.

Simmons, D. J., J. E. Russell, F. Winter, P. T. Van, A. Vignery, R. Baron, G. D. Rosenberg, and W. V. Walker. Effect of spaceflight on the non-weight-bearing bones of rat skeleton. Am. J. Physiol. 244: R319-326, 1983.

Smith, A. H. Principles of Gravitational Biology. In: Foundations of Space Biology and Medicine, M. Calvin and O. G. Gazenko, Eds., NASA, Washington, DC, 1975, Vol. II, Book 1, pp. $129-162$.

Spector, M., R. T. Turner, E. Morey-Holton, D. J. Baylink, and N. H. Bell. Arrested bone formation during space flight results in a hypomineralized skeletal defect. The Physiologist 26: S110-S111, 1983.

Spengler, D. M., E. R. Morey, D. R. Carter, R. T. Turner, and D. J. Baylink. Effects of spaceflight on structural and material strength of growing bone. Proc. Soc. Exptl. Biol. Med. 174: 224-228, 1983.

Stewart, A. F., M. Adler, C. M. Byers, G. V. Segre, and A. E. Broadus. Calcium homeostasis in immobilization: an example of resorptive hypercalciuria. N. Engl. J. Med. 306: 1136-1140, 1982. 
Stupakov, G. P., V. S. Kazeykin, A. P. Kozlovskiy, and V. V. Korolev. Evaluation of changes in human axial skeletal bone structures during long-term spaceflights. Space Biol. Med. 18: 4247, 1984.

Termine, J. D. Bone matrix proteins and the mineralization process. In: Primer on the Metabolic Bone Diseases and Disorders of Mineral Metabolism, M. J. Favus, ed., Am. Soc. Bone Mineral Res., Kelseyville, CA, First Edition, 1990, pp. 16-22.

Thompson, D. W. On Growth and Form. Cambridge University Press, New York, 1917 (Revised, Bonner, J.T., Ed., 1961).

Thornton, W. E. and J. Ord. Physiological mass measurements in Skylab. In: Biomedical Results from Skylab, R. S. Johnston and L. F. Dietlein, eds., NASA SP-377, Washington, DC, 1977, pp. 175-182.

Tilton, F. E., J. J. C. Degiganni, and V. S. Schneider. Long-term follow-up of Skylab bone demineralization. Aviat. Space Environ. Med. 51: 1209-1213, 1980.

Tumer, R. T., N. H. Bell, P. Duvall, J. D. Bobyn, M. Spector, E. Morey-Holton, and D. J. Baylink. Spaceflight results in formation of defective bone. Proc. Soc. Exptl. Biol. Med. 180: 544-549, 1985a.

Turner, R. T., G. K. Wakley, and B. W. Szukalski. Effects of gravitational and muscular loading on bone formation in growing rats.The Physiologist 28: S67-S68; 1985 b.

Vailas, A. C., D. M. DeLuna, L. L. Lewis, S. L. Curwin, R. R. Roy, and E. K. Alford. Adaptation of bone and tendon to prolonged hindlimb suspension in rats. J. Appl. Physiol. 65: 373-376, 1988.

Vailas, A. C., R. F. Zernicke, R. E. Grindeland, A. Kaplansky, G. N. Durnova, K. C. Li, and D. A. Martinez. Effects of spaceflight on rat humerus geometry, biomechanics, and biochemistry. FASEB J. 4: 47-54, 1990a.

Vailas, A. C., R. F. Zernicke, R. E. Grindeland, and K.-C. Li. Suspension effects on rat femur-medial collateral ligament-tibia unit. Am. J. Physiol. 258: R724-R728, $1990 \mathrm{~b}$.

Vico, L., A. V. Bakulin, and C. Alexandre. Does 7-day hindquarters unloading simulate 7-day of weightlessness exposure in rat trabecular bone? Proc. 3rd European Symposium on Life Sciences Research in Space, Graz, Austria, 1987a (ESA SP-271), pp. 179-182.

Vico, L., Chappard, D., Alexandre, C., Palle, S., Minaire, P., Riffat, G., Morukov, B. and Rakhmanov, S. Effects of a 120-day period of bed rest on bone mass and bone cell activities in man: Attempts at countermeasure. Bone and Mineral 2: 383-394, $1987 \mathrm{~b}$.

Vico, L., D. Chappard, C. Alexandre, S. Palle, P. Minaire, G. Riffat, V. E. Novikov, and A. V. Bakulin. Effects of weightlessness on bone mass and osteoclast number in pregnant rats after a five-day spaceflight (Cosmos 1514). Bone 8: 95-103, $1987 \mathrm{c}$. 
Vico, L., D. Chappard, S. Palle, A. V. Bakulin, V. E. Novikov, and C. Alexandre. Trabecular bone remodeling after seven days of weightlessness exposure (BIOCOSMOS 1667). Am. J. Physiol. 255: R243-R247, 1988.

Vogel, J. M., M. W. Whittle, M. C. Smith, Jr., and P. C. Rambaut. Bone mineral measurementexperiment M078. In:Biomedical Results from Skylab, R. S. Johnston and L. F. Dietlein, eds., NASA SP-377, Washington, DC, 1977, pp. 183-190.

Whedon, G. D., L. Lutwak, P. C. Rambaut, M. W. Whittle, M. C. Smith, J. Reid, C. S. Leach, C. R. Stadler, D. D. Sanford. Mineral and nitrogen metabolic studies, experiment M071. In: Biomedical Results from Skylab, R. S. Johnston and L. F. Dietlein, eds., NASA SP-377, Washington, DC, 1977, pp. 164-174.

Whedon, G. D. Metabolic and endocrine hormone studies in manned space flight. In:Molecular Endocrinology, I. MacIntyre and T. Szelke, eds., Elsevier/North Holland Biomedical Press, New York, 1979, pp. 229-250.

Wolff, J. The Classic: Concerning the Interrelationship Between Form and Function of the Individual Parts of the Organism. Clin. Orthopaed. 228: 2-11, 1988 (translated by Max Scheck from Wolff, J. Über die Wechselbeziehungen Zwischen der Form und der Function der Einzelnen Gebilde des Organismus. Leipzig, FCW. Vogel, 1901).

Wronski, T. J. and E. R. Morey-Holton. Skeletal response to simulated weightlessness: a comparison of suspension techniques. Aviat. Space Environ. Med. 58: 63-68, 1987.

Wronski, T. J. and E. R. Morey. Effect of spaceflight on periosteal bone formation in rats. Am. J. Physiol. 244: R305-R309, 1983a.

Wronski, T. J. and E. R. Morey. Recovery of the rat skeleton from the adverse effects of simulated weightlessness. Metab. Bone Dis. \& Rel.Res. 4: 347-352, $1983 \mathrm{~b}$.

Wronski, T. J., and E. R. Morey. Skeletal abnormalities in rats induced by simulated weightlessness. Metab. Bone Dis. \& Rel. Res. 4: 69-75, 1982.

Wronski, T. J., E. R. Morey-Holton, S. B. Doty, A. C. Maese, and C. C. Walsh. Spacelab 3: Histomorphometric analysis of rat skeleton following spaceflight. Am. J. Physiol. 252: R252-R255, 1987.

Yagodovsky, V. A., L. A. Triftanidi, and G. P. Gorokhova. Space flight effects on skeletal bones of rats (light and electron microscopic examination). Aviat. Space Environ. Med. 47: 734-738, 1976.

Zernicke, R. F., A. C. Vailas, R. E. Grindeland, A. Kaplansky, G. J. Salem, and D. A. Martinez. Spaceflight effects on biomechanical and biochemical properties of rat vertebrae. Am. J. Physiol. 258: R1327-1332,1990. 

Devie Highway, Suite 1204. Arlington, VA 22202-4302, and to the Office of Management and Budget, Paperwork Raduction Project (0704-0188). Washington, DC 20503.
1. AGENCY USE ONLY (Leave blank)
2. REPOAT DATE
December 1991
3. REPORT TYPE AND DATES COVERED
Technical Memorandum

4. TITLE AND SUBTTTLE

Skeletal Responses to Spaceflight

6. AUTHOR(S)

$199-40-42-01$

Emily Morey-Holton and Sara B. Arnaud

7. PERFORMING ORGANIZATION NAME(S) AND ADDRESS(ES)

8. PERForming ORgaNization REPOAT NUMBER

Ames Research Center

Moffett Field, CA 94035-1000

A-91232

9. SPONSORINQMONTORING AGENCY NAME(S) AND ADDAESS(ES)

10. SPONSORING/MONITOAING AGENCY REPORT NUMBER

National Aeronautics and Space Administration

Washington, DC 20546-0001

NASA TM- 103890

11. SUPPLEMENTAAY NOTES

Point of Contact: Emily Morey-Holton, Ames Research Center, MS 236-7, Moffett Field, CA 94035-1000; (415) 6045471 or FTS 4645471

12a. DISTAIBUTION/AVAILABILITY BTATEMENT

12b. DISTRIBUTION CODE

Unclassified - Unlimited

Subject Category 52

13. ABSTRACT (Maximum 200 words)

The role of gravity in the determination of bone structure has been elucidated by observations in adult humans and juvenile animals during and after spaceflight. The response of the skeleton to a new environment that imposes different biomechanical stresses is complicated by the skeleton's dual function as a support structure and as a mineral reservoir. The transport of minerals is regulated and influenced by organ systems (i.e., cardiovascular, muscular, renal, gastrointestinal) whose anatomy and metabolism are also affected by microgravity. This review deals almost exclusively with the observed and potential effects of spaceflight on bone, but some findings from other body systems are also cited. The primary response of bone tissue to microgravity is at the interface of mineral and matrix, in the process of biomineralization. This response is manifested by demineralization or retarded growth in some regions of the skeleton, and hypermineralization in others. The most pronounced effects are seen in the heel bone and the skull, the most distally located bones relative to the heart. Whereas quantitative losses of mineral from the whole skeleton are relatively small, regional or localized areas of change during spaceflight could seriously impair the support function of the skeleton on return to Earth. Ground-based flight simulation models (head-down bed rest (human) and the rat tail-traction system) that focus on changes in bone structure at the molecular, organ, and whole-body levels are described and compared to flight results. On Earth, the morphologic and compositional changes in the unloaded bones are very similar to changes during flight; however, the ground-based changes appear to be more transient. In addition, a redistribution of bone mineral in gravity-dependent bones occurs both in space and during head-down positioning on Earth. Longitudinal data have provided considerable information on the influence of endocrine and muscular changes on bone structure after unloading.

14. SUBJECT TERMS
Serum biomineralization, Biomechanics, Bed rest, Bone mineral redistribution

15. NUMBER OF PAGES

34

16. PRICE CODE

$\mathrm{A03}$

17. SECURITY CLASSIFICATION

OF REPORT

Unclassified

18. SECURITY CLASSIFICATION

19. SECUAITY CLASSIFICATION

20. LIMITATION OF ABSTRACT OF THIS PAQE

Unclassified 